\title{
Home mechanical ventilation: A Canadian Thoracic Society clinical practice guideline
}

\author{
Douglas A McKim MD FRCPC FCCP DABSM1, Jeremy Road BSc MD FRCPC ${ }^{2}$, Monica Avendano MD FRCPC ${ }^{3}$, \\ Steve Abdool BA MA PhD $(C)^{3,4}$, Fabien Côté MD FRCPC $\mathrm{CHA}^{5}$, Nigel Duguid MB ChB FRCPC MRCP6, \\ Janet Fraser BSC RRT ${ }^{7}$, François Maltais MD FRCPC ${ }^{8}$, Debra L Morrison MD FRCPC ${ }^{9}$, Colleen O'Connell MD FRCPC ${ }^{10}$, \\ Basil J Petrof MD FRCPC ${ }^{11}$, Karen Rimmer MD FRCPC ${ }^{12}$, Robert Skomro MD FRCP DABSM ${ }^{13}$; \\ Canadian Thoracic Society Home Mechanical Ventilation Committee
}

\begin{abstract}
DA McKim, J Road, M Avendano, et al; Canadian Thoracic Society Home Mechanical Ventilation Committee. Home mechanical ventilation: A Canadian Thoracic Society clinical practice guideline. Can Respir J 2011;18(4):197-215.

Increasing numbers of patients are surviving episodes of prolonged mechanical ventilation or benefitting from the recent availability of userfriendly noninvasive ventilators. Although many publications pertaining to specific aspects of home mechanical ventilation (HMV) exist, very few comprehensive guidelines that bring together all of the current literature on patients at risk for or using mechanical ventilatory support are available. The Canadian Thoracic Society HMV Guideline Committee has reviewed the available English literature on topics related to HMV in adults, and completed a detailed guideline that will help standardize and improve the assessment and management of individuals requiring noninvasive or invasive HMV. The guideline provides a disease-specific review of illnesses including amyotrophic lateral sclerosis, spinal cord injury, muscular dystrophies, myotonic dystrophy, kyphoscoliosis, post-polio syndrome, central hypoventilation syndrome, obesity hypoventilation syndrome, and chronic obstructive pulmonary disease as well as important common themes such as airway clearance and the process of transition to home. The guidelines have been extensively reviewed by international experts, allied health professionals and target audiences. They will be updated on a regular basis to incorporate any new information.
\end{abstract}

Key Words: Airway clearance strategies; Amyotrophic lateral sclerosis; Central hypoventilation syndrome; Chronic obstructive pulmonary diseases; Duchenne muscular dystrophy; Ethics; Home mechanical ventilation; Kyphoscoliosis; Muscular dystrophies; Myopathies; Myotonic dystrophy; Obesity hypoventilation syndrome; Post-polio syndrome; Prolonged mechanical ventilation; Spinal cord injury; Steinert's muscular dystrophy; Transition to home

$\mathrm{M}$ ore than 50 years ago, individuals with polio courageously led the challenge of maintaining mechanical ventilation outside of institutions and quietly initiated a more independent, patient-centered and collaborative approach to respiratory health care. Today, the drivers for home mechanical ventilation (HMV) are different. The rising costs of hospital care, the advent of commercially available noninvasive masks and positive-pressure ventilators have fuelled greater demand for HMV. However, the desire of individuals to maintain a quality of life (QoL) in their homes remains the prevailing impetus. The present HMV clinical practice guideline is intended to be a resource for physicians, health care providers, policy makers and individuals at risk for or currently

\section{La ventilation mécanique à domicile : un guide de pratique clinique de la Société canadienne de thoracologie}

De plus en plus de patients survivent à des épisodes de ventilation mécanique prolongés ou profitent de l'accès récent à des ventilateurs non effractifs conviviaux. Même s'il existe de nombreuses publications sur des aspects précis de la ventilation mécanique à domicile (VMD), très peu de lignes directrices complètes rassemblent toutes les publications à jour sur les patients vulnérables à l'utilisation d'un soutien ventilatoire mécanique. Le comité des lignes directrices sur la VMD de la Société canadienne de thoracologie a analysé les publications anglophones disponibles sur les sujets liés à la VMD chez les adultes et a élaboré des lignes directrices détaillées qui contribueront à normaliser et à améliorer l'évaluation et la prise en charge des personnes ayant besoin d'une VMD non effractive ou effractive. Les lignes directrices fournissent une analyse propre à certaines maladies, y compris la sclérose latérale amyotrophique, le traumatisme médullaire, la dystrophie musculaire, la dystrophie myotonique, la cyphoscoliose, le syndrome post-polio, le syndrome d'hypoventilation centrale, le syndrome obésité-hypoventilation et la maladie pulmonaire obstructive chronique, et abordent des thèmes courants importants, tels que la clairance des voies aériennes et le processus de transition vers le domicile. Les guides de pratique ont fait l'objet de révisions approfondies par des experts internationaux, des professionnels paramédicaux et des publics ciblés. Ils seront régulièrement mis à jour afin d'y intégrer toute nouvelle information.

\footnotetext{
${ }^{1}$ Division of Respirology, University of Ottawa, and Respiratory Rehabilitation Services, Ottawa Hospital Sleep Centre, Ottawa, Ontario; ${ }^{2}$ Division of Respiratory Medicine and The Lung Centre, University of British Columbia, Provincial Respiratory Outreach Program, Vancouver, British Columbia; ${ }^{3}$ Respiratory Medicine, West Park Healthcare Centre, University of Toronto; ${ }^{4}$ Centre for Clinical Ethics at St Michael's Hospital, West Park Healthcare Centre, and University of Toronto, Toronto, Ontario; ${ }^{5}$ Laval University, Québec, Québec; ${ }^{6}$ Eastern Health, Memorial University, St John's, Newfoundland and Labrador; ${ }^{7}$ Respiratory Therapy Services, West Park Healthcare Centre, Toronto, Ontario; ${ }^{8}$ Research Centre, University Institute of Cardiology and Lung Health for Québec, Laval University, Québec, Québec; ${ }^{9}$ Sleep Clinic and Laboratory, Queen Elizabeth II Health Sciences Centre and Dalhousie University, Halifax, Nova Scotia; ${ }^{10}$ Stan Cassidy Centre for Rehabilitation, Fredericton, New Brunswick; ${ }^{11}$ McGill University Health Centre, Montreal, Quebec; ${ }^{12}$ University of Calgary, Calgary, Alberta; ${ }^{13}$ University of Saskatchewan, Saskatoon, Saskatchewan

Correspondence: Dr Douglas A McKim, Division of Respirology, University of Ottawa, 501 Smyth Road, Unit 1201, Ottawa, Ontario K1H 8M2. Telephone 613-737-8899 ext 75318, fax 613-736-9054, e-mail dmckim@ottawahospital.on.ca

Reprint requests: Canadian Thoracic Society, 300-1750 Courtwood Crescent, Ottawa, Ontario K2C 2B5. Telephone 613-569-6411, fax 613-569-8860, e-mail cts info@lung.ca
} 
there are extremely few prospective or randomized trials. As a result, most recommendations are based on retrospective or descriptive studies and, to a great extent, on consensus of the CTS HMV committee.

Recommendations strive to achieve a balance between an exceptional standard of care illustrated in the literature and the reality of health care in Canada, where geographical and economic barriers may require compromise to ensure the availability of the best care possible. This approach may also allow greater applicability to jurisdictions where, for example, polysomnography may be unavailable or so difficult to obtain as to present unacceptable barriers to appropriate, timely introduction of noninvasive ventilation (NIV). Nevertheless, some subjects considered to be important by the committee are not addressed in the literature. Some jurisdictions have access to provincial ventilator pools, in which equipment and knowledgeable health care professionals are available at relatively minimal cost, to ensure the success of HMV. The literature does not address questions regarding government-funded equipment pools. On important issues for which literature is lacking, but strong expert opinion was available, recommendations were made by the HMV Guideline Committee.

No article in the literature, to our knowledge, addressed the appropriate addition of a backup ventilation system aside from patients fully ventilated through a tracheostomy; accordingly, it remains uncertain as to precisely when an individual on NIV should have an additional ventilator or when alarms should be required. The general recognition that NIV is not designed for full $24 \mathrm{~h}$ life support has resulted in this uncertainty. However, patients are, in fact, using 24 h NIV, without which they are at risk for acute respiratory failure. This area of risk management will need attention in future investigations. Throughout the recommendations, it is assumed (aside from that clearly stated in the section on Transition to Home) that appropriate training will be provided to patients and caregivers.

These guidelines do not address negative-pressure body ventilators or abdominal ventilators because positive-pressure ventilators have, with few exceptions, completely replaced negative-pressure ventilators in the home. Although potentially of significant clinical value in the follow-up of patients on NIV, no recommendations are made on the use of digital information and downloads from bilevel devices. Additional research is desperately needed to address many of these critical questions.

The present guideline focused on HMV in the adult population. There are some important differences in HMV in the pediatric population and also in the transition phase into adult programs. The committee recognized these areas and hope that future guidelines will address them.

Preventive airway management and HMV is a complex, interdisciplinary component of respiratory care and clinical practice. This component requires a continuum of chronic disease management involving many layers of expertise from government and professional education to home care services, acute and chronic health facilities and independent living facilities. The goal of HMV - and, thereby the goal of these guidelines - is to ensure the continued health of patients at risk for and currently using ventilatory support in their homes where $\mathrm{QoL}$ is greater and the cost to the health care system is the lowest.

The present document represents the executive summary of the guideline. The source document, which is more detailed and includes research questions identified by the committee, is available online at www.respiratoryguidelines.ca/guideline/home-ventilation.

\section{EXECUTIVE SUMMARY}

\section{Question}

What evidence is available to inform the practice of HMV and lead to better individual, caregiver and system outcomes?

\section{Objective}

The objective of the present clinical practice guideline is to provide guidance on the role of mechanical ventilation in the home setting. A guideline on this topic is needed to inform best practices, provide a basis to identify gaps in care and provide direction for future research.

\section{Target population}

The current clinical practice guideline applies to all adult individuals who are at risk for or are using HMV. Individuals with amyotrophic lateral sclerosis (ALS), central hypoventilation syndrome (CHS), chronic obstructive pulmonary disease (COPD), kyphoscoliosis, obesity hypoventilation syndrome (OHS), spinal cord injury (SCI), Duchenne muscular dystrophy (DMD), muscular dystrophies (MDs) other than DMD, myopathies and myotonic dystrophy (Steinert's muscular dystrophy [SMD]) are of special interest and are considered individually in the present clinical practice guideline.

\section{Target users}

The present clinical practice guideline is intended for use by the health care teams that care for individuals who are at risk for or require ventilatory assistance. Respirologists, physiatrists, neurologists, family practitioners, nurses, respiratory therapists, physiotherapists and other health care professionals can use these guidelines to help inform their clinical practice with regard to HMV. This guideline is also intended for use by ventilator-assisted individuals (VAIs) and their caregivers to help them make informed decisions with regard to HMV.

\section{Guideline development}

\section{METHODOLOGY}

This clinical practice guideline was developed according to the convention of the 23-item AGREE II instrument - the current gold standard in the appraisal of practice guidelines (1). The HMV Expert Committee, comprising respirologists, a physiatrist and a respiratory therapist with content expertise in each of the topic areas, a research coordinator and a methodologist conducted a systematic review of the literature that was current to June 2010. Before completion, the guideline was distributed to content experts in Canada and other countries with similar programs for the opportunity to provide feedback concerning the collection and interpretation of the evidence, as well as the development and content of the recommendations. Key stakeholders, from the Ministry of Health, VAIs, interested groups including respiratory therapists, ALS, MD and spinal cord networks were invited to review and provide input on the document. Final consensus on the recommendations from the CTS HMV Committee was reached through a formal voting process that was anonymized. The literature will be periodically reviewed (biannually) and the guideline will be updated as new or compelling evidence is identified.

\section{Literature search strategy}

The literature was searched using MEDLINE (OVID: 1980 through June 2010), Embase OVID: (1980 through June 2010), HealthStar (1980 through June 2010), the Cochrane Library (OVID: Issue 1, 2009), the Canadian Medical Association InfoBase and the National Guideline Clearinghouse. Reference lists of related papers and recent review articles were also scanned for additional citations.

\section{Study selection criteria}

Articles were selected for inclusion in the systematic review of the evidence if they reported data on the role of HMV among adult individuals who require ventilatory assistance. Studies were required to report data on at least one of the following outcomes of interest: survival, pulmonary function, sleep parameters, airway clearance techniques, cognition, VAIs and caregiver QoL, making the transition to home or ethical considerations.

\section{Critical appraisal}

The strengths and weaknesses of the evidence were carefully considered in the generation of the recommendations. Although the majority of the evidence in this topic area is modest, the Grading of Recommendations Assessment, Development and Evaluation (GRADE) methodology was used to inform the generation of recommendations and critically appraise the strength of the evidence (2). When no evidence was available, the committee made a recommendation when consensus was reached; the recommendation was subsequently identified as such (Table 1). 
TABLE 1

Grading recommendations

\begin{tabular}{|c|c|c|c|}
\hline $\begin{array}{l}\text { Grade of recommendation/ } \\
\text { description }\end{array}$ & Benefit versus risk and burdens & $\begin{array}{l}\text { Methodological quality of } \\
\text { supporting evidence }\end{array}$ & Implications \\
\hline $\begin{array}{l}\text { 1A/strong recommendation, } \\
\text { high-quality evidence }\end{array}$ & $\begin{array}{l}\text { Benefits clearly outweigh risk and } \\
\text { burdens, or vice versa }\end{array}$ & $\begin{array}{l}\text { RCTs without important limitations or } \\
\text { overwhelming evidence from observational } \\
\text { studies }\end{array}$ & $\begin{array}{l}\text { Strong recommendation, can apply to most } \\
\text { patients in most circumstances without } \\
\text { reservation }\end{array}$ \\
\hline $\begin{array}{l}\text { 1B/strong recommendation, } \\
\text { moderate quality evidence }\end{array}$ & $\begin{array}{l}\text { Benefits clearly outweigh risk and } \\
\text { burdens or vice versa }\end{array}$ & $\begin{array}{l}\text { RCTs with important limitations (inconsistent } \\
\text { results, methodological flaws, indirect or } \\
\text { imprecise) or exceptionally strong evidence } \\
\text { from observational studies }\end{array}$ & $\begin{array}{l}\text { Strong recommendation, can apply to most } \\
\text { patients in most circumstances without } \\
\text { reservation }\end{array}$ \\
\hline $\begin{array}{l}\text { 1C/strong recommendation, } \\
\text { low-quality or very } \\
\text { low-quality evidence }\end{array}$ & $\begin{array}{l}\text { Benefits clearly outweigh risk and } \\
\text { burdens, or vice versa }\end{array}$ & Observational studies or case series & $\begin{array}{l}\text { Strong recommendation but may change } \\
\text { when higher quality evidence becomes } \\
\text { available }\end{array}$ \\
\hline $\begin{array}{l}\text { 2A/weak recommendation, } \\
\text { high-quality evidence }\end{array}$ & $\begin{array}{l}\text { Benefits closely balanced with risks and } \\
\text { burden }\end{array}$ & $\begin{array}{l}\text { RCTs without important limitations or } \\
\text { overwhelming evidence from observational } \\
\text { studies }\end{array}$ & $\begin{array}{l}\text { Weak recommendation, best action may } \\
\text { differ depending on circumstances, } \\
\text { patients' or social values }\end{array}$ \\
\hline $\begin{array}{l}\text { 2B/weak recommendation, } \\
\text { moderate-quality evidence }\end{array}$ & $\begin{array}{l}\text { Benefits closely balanced with risks and } \\
\text { burden }\end{array}$ & $\begin{array}{l}\text { RCTs with important limitations (inconsistent } \\
\text { results, methodological flaws, indirect or } \\
\text { imprecise) or exceptionally strong evidence } \\
\text { from observational studies }\end{array}$ & $\begin{array}{l}\text { Weak recommendation, best action may } \\
\text { differ depending on circumstances, } \\
\text { patients' or social values }\end{array}$ \\
\hline $\begin{array}{l}\text { 2C/weak recommendation, } \\
\text { low-quality or very } \\
\text { low-quality evidence }\end{array}$ & $\begin{array}{l}\text { Uncertainty in the estimates of benefits, } \\
\text { risks and burden; benefits, risk and } \\
\text { burden may be closely balanced }\end{array}$ & Observational studies or case series & $\begin{array}{l}\text { Very weak recommendations; other } \\
\text { alternatives may be equally reasonable }\end{array}$ \\
\hline
\end{tabular}

From reference 2. RCTs Randomized controlled trials

\section{REFERENCES}

1. Brouwers M, Kho ME, Browman GP, et al; for the AGREE Next Steps Consortium. AGREE II: Advancing guideline development, reporting and evaluation in healthcare. Can Med Assoc J 2010;182:E839-42.

2. Guyatt G, Gutterman D, Baumann M, et al. Grading strength of recommendations and quality of evidence in clinical guidelines: Report from an American College of Chest Physicians Task Force. Chest 2006;129:178-81.

\section{SECTION I. AIRWAY CLEARANCE IN AT-RISK AND VAIs}

\section{Introduction}

Ventilatory support is capable of reliably providing volume and pressure for adequate ventilation, but this can only be assured if the airways remain clear of mucus and debris. Airways encumbered by secretions will result in reduced ventilation and contribute to low ventilation/perfusion states, which in turn, can lead to resorption atelectasis and shunt. Retained secretions increase the risk for pneumonia and respiratory failure. During long-term invasive tracheostomy ventilation, airway clearance (usually by suctioning) is routine. However, during NIV, there is a tendency to neglect the need for airway clearance techniques and focus on ventilation alone. In neuromuscular disease (NMD) patients, recognizing this principle is equally important - even before the need for ventilatory support - and is critical in addressing the issues of worsening respiratory mechanics and the inability to cough effectively.

\section{Key evidence}

Prospective observational studies and retrospective reviews based on small numbers of patients comprise most of the evidence base for airway clearance in at-risk and VAIs. In the absence of high-quality evidence, the strength of the recommendations was determined by consensus within the committee.

Education and preventive strategies in airway clearance must precede the need for mechanical ventilation whenever possible. Education in preventive airway clearance helps prepare a patient and may prevent acute crises. In the absence of contraindications such as risk for barotrauma or unconsciousness, lung volume recruitment (LVR [ie, air stacking]) techniques should be introduced with measurement of peak cough flows (PCFs) and maximum insufflation capacity (MIC) $(1,2)$ in those with PCFs $<270 \mathrm{~L} / \mathrm{min}$. Figure 1-1 illustrates the important difference between spontaneous vital capacity (VC [red curve]) and after LVR (MIC [blue curve]) in kyphoscoliosis (post-polio) and tetraplegia. There is a lower volume response in more mechanically restricted individuals with kyphoscoliosis.

This recommendation is informed by three retrospective cohort studies, one case series and one consensus document (1-5). Bach et al (1) studied 22 and 24 DMD, pre- and post-protocol patients, respectively. Kang and Bach (2) studied 71 preprotocol and 23 protocol NMD patients. Tzeng and Bach (3) studied 43 mixed NMD patients by performing air-stacking and MIC measurements. More recently, a case series (4) demonstrated that $94.9 \%$ of 78 DMD patients were capable of significantly increasing their PCFs with LVR. There was also one consensus document from the American Thoracic Society (5).

Manually assisted coughing (MAC) is recommended alone or in combination with LVR to increase PCFs to $>270 \mathrm{~L} / \mathrm{min}$. From the two observational studies that informed this recommendation $(6,7)$, one (21 patients with NMD [6]) demonstrated that LVR and MAC may significantly increase cough capacity; the other (61 DMD patients [7]) demonstrated significant increases in PCF with MAC and in combination with air stacking. One consensus document suggested a minimum desirable PCF of $270 \mathrm{~L} / \mathrm{min}$ (5). In the absence of contraindications (as above), mechanical in-exsufflation (MI-E) is recommended for patients unable to achieve PCFs $>270 \mathrm{~L} / \mathrm{min}$ with LVR and/or MAC, particularly during respiratory infection. Evidence includes one observational intervention study (21 patients with NMD [6]) that demonstrated that peak expiratory flows can be significantly increased above those with LVR and MAC with use of MI-E. The other evidence is one retrospective cohort study of $22 \mathrm{NMD}$ patients who were provided standard care and 24 patients on 'protocol', which included the use of MI-E, and demonstrated fewer hospital days (1). One case report described the use of MI-E to treat respiratory failure during lower respiratory infection in ALS (8). A retrospective cohort study of 41 patients with NMD demonstrated significant reductions in subsequent hospital days whether on spontaneous, part-time support or full-time NIV, once initiated on a respiratory protocol that included MI-E (3). This approach is summarized in Figure 1-2.

For invasive ventilation, long-term tracheostomies should be cuffless or cuff deflated, if possible. One observational study (9) demonstrated the safety and value of uncuffed or cuffless tracheostomy 


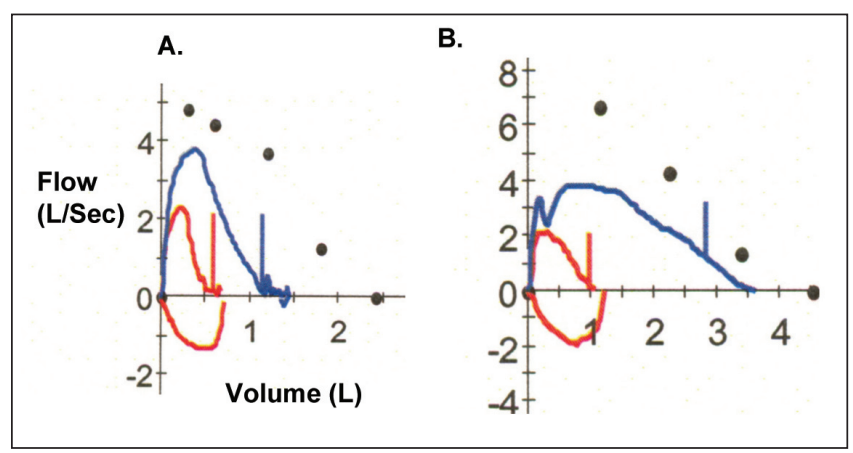

Figure 1-1) Flow volume loops of individuals with kyphoscoliosis (postpolio) (A) and tetraplegia (B). Spontaneous vital capacity (red) and maximum insufflation capacity with lung volume recruitment (blue)

tubes. Unless contraindicated due to aspiration risk, cuffless ventilation allows for the use of speaking valves to augment speech as well as allowing for independent performance of LVR techniques; however, adequate, sustained gas exchange must be ensured (8). For invasive ventilation, heated humidity is recommended over a heathumidity exchanger. Three prospective randomized trials involving 14, 24 and 15 spontaneously and 11 fully ventilated patients, respectively (10-12), demonstrated adverse effects of heat-humidity exchangers on dead space, minute ventilation and respiratory rate, which are particularly relevant to patients with spontaneous ventilation. Furthermore, a meta-analysis (13) did not find significant differences in important clinical outcomes such as pneumonia, mortality or morbidity.

Insufficient evidence exists in long-term tracheostomy-ventilated patients to fully inform the technique of tracheostomy suctioning. The committee recommends that minimally invasive suctioning - instead of deep suctioning - be used when possible. One consensus document indicated the effectiveness of shallow suctioning in patients with some cough ability (14), and a randomized controlled trial (RCT) of intensive care unit-ventilated patients demonstrated the equivalence of minimally invasive suctioning with fewer adverse effects (15). MI-E and MAC for tracheostomy airway clearance should be strongly considered to complement or replace deep suctioning. This recommendation is informed by one retrospective $(n=18)$, one prospective crossover $(n=8)$ and one prospective controlled trial ( $n$ not specified) (16-18) demonstrating that MI-E for tracheal clearance is both effective and preferred by patients familiar with both MI-E and invasive suctioning. Clean, as opposed to sterile, conditions are adequate for home secretion clearance and suctioning. Two professional consensus documents suggest that a fully sterile environment is not necessary for tracheostomy management in the home, but that clean conditions are adequate $(19,20)$.

\section{Conclusion}

Adequate airway clearance may be the single most critical therapeutic intervention that prevents acute respiratory failure, undesired intubation and tracheostomy in patients at risk for or using NIV. Airway clearance strategies may help to maintain lung and chest wall compliance through its positive effects on MIC (21) and peak expiratory flows. Individuals who are at greatest risk are those with impairment of inspiratory and expiratory muscles and glottic dysfunction. Many noninvasive techniques are well established including LVR, MAC and MI-E. Several of these noninvasive strategies can also be applied to tracheostomy-ventilated patients in whom cuff inflation and invasive suctioning have traditionally been the sole method of ventilation and airway clearance. More research is needed to identify the ideal methods of noninvasive and invasive airway clearance in the home to optimize the effectiveness of mechanical ventilation and enhance QoL for VAIs.

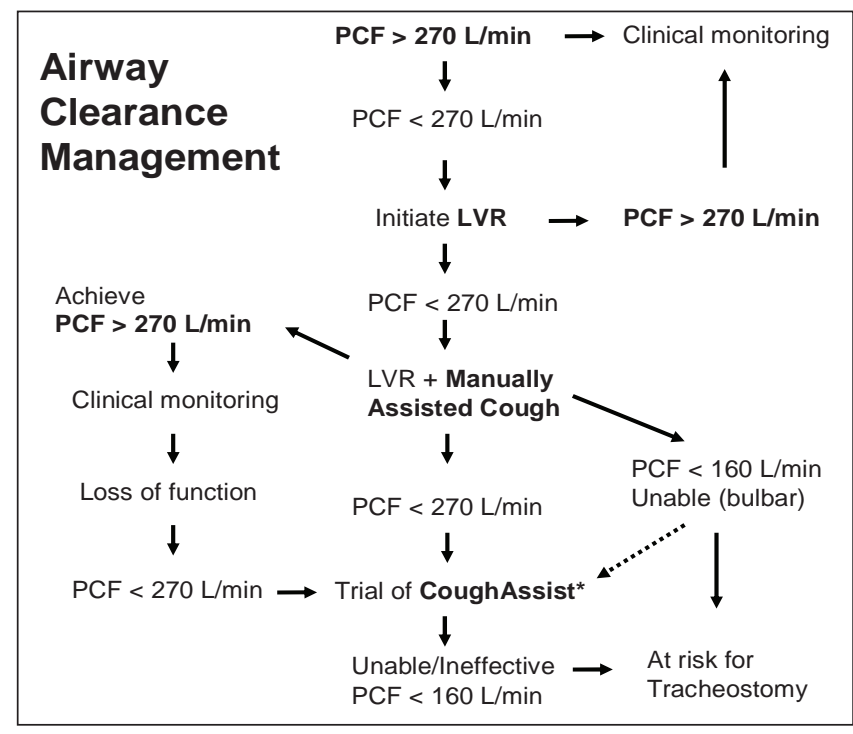

Figure 1-2) Flow diagram for preventive airway clearance techniques. LVR Lung volume recruitment; PCF Peak cough flow. *Philips Healthcare, USA

\section{SECTION I. RECOMMENDATIONS}

For at-risk individuals and patients using NIV:

1. Education and preventive strategies in airway clearance must precede the need for mechanical ventilation whenever possible. (Consensus)

2. In the absence of contraindications, LVR techniques should be introduced with the measurement of PCFs and MIC in those with PCFs $<270 \mathrm{~L} / \mathrm{min}$. (Grade of recommendation 1C)

3. MAC is recommended alone or in addition to LVR to increase PCFs to $>270 \mathrm{~L} / \mathrm{min}$. (Grade of recommendation 1C)

4. In the absence of contraindications, MI-E should be recommended for patients unable to achieve PCFs $>270 \mathrm{~L} / \mathrm{min}$ with LVR and/or MAC, particularly during respiratory infection. (Grade of recommendation 1C)

For invasive ventilation:

1. As long as adequate, sustained ventilation is ensured, long-term tracheostomies should be cuffless or cuff deflated if possible. (Grade of recommendation 2C)

2. Heated humidity is recommended over heat-humidity exchangers. (Grade of recommendation 1A)

3. Minimally invasive rather than deep suctioning is recommended when possible. (Grade of recommendation 2B)

4. MI-E and MAC for tracheostomy airway clearance should be strongly considered through tracheostomy to complement or replace deep suctioning. (Grade of recommendation 1C)

5. Clean, as opposed to sterile, conditions are adequate for home secretion clearance and suctioning. (Consensus)

\section{REFERENCES}

1. Bach JR, Ishikawa Y, Kim H. Prevention of pulmonary morbidity for patients with Duchenne muscular dystrophy. Chest 1997;112:1024-8.

2. Kang SW, Bach JR. Maximum insufflation capacity.

Chest 2000;118:61-5.

3. Tzeng AC, Bach JR. Prevention of pulmonary morbidity for patients with neuromuscular disease. Chest 2000;118:1390-6.

4. Bach JR, Bianchi C, Vidigal-Lopes M, et al. Lung inflation by glossopharyngeal breathing and "air stacking" in Duchenne muscular dystrophy. Am J Phys Med Rehabil 2007;86:295-300. 
5. Finder JD, Birnkrant D, Carl J; American Thoracic Society. Respiratory Care of the Patient with Duchenne Muscular dystrophy; ATS Consensus Statement. Am J Respir Crit Care Med 2004;170:456-65.

6. Bach JR. Mechanical insufflation-exsufflation. Comparison of peak expiratory flows with manually assisted and unassisted coughing techniques. Chest 1993;104:1553-62.

7. Ishikawa Y, Bach JR, Komaroff E, et al. Cough augmentation in Duchenne muscular dystrophy. Am J Phys Med Rehabil 2008;87:726-30.

8. Servera E, Sancho J, Gómez-Merino E, Briones ML, et al. Non-invasive management of an acute chest infection for a patient with ALS. Neurol Sci 2003;209:111-3.

9. Bach JR, Alba AS. Tracheostomy ventilation. A study of efficacy of deflated cuffs and cuffless tubes. Chest 1990;97:679-83.

10. Pelosi P, Solca M, Ravagnan I, et al. Effects of heat and moisture exchangers on minute ventilation, ventilatory drive, and work of breathing during pressure-support ventilation in acute respiratory failure. Crit Care Med 1996;24:1184-8.

11. Jaber S, Chanques G, Matecki S, et al. Comparison of the effects of heat and moisture exchangers and heated humidifiers on ventilation and gas exchange during non-invasive ventilation. Intensive Care Med 2002;28:1590-4.

12. Campbell RS, Davis K Jr, Johannigman JA, et al. The effects of passive humidifier dead space on respiratory variables in paralyzed and spontaneously breathing patients. Respir Care 2000;45:306-12.

13. Siempos II, Vardakas KZ, Kopterides P, et al. Impact of passive humidification on clinical outcomes of mechanically ventilated patients: A meta-analysis of randomized controlled trials. Crit Care Med 2007;35:2843-51.

14. Day T, Farnell S, Wilson-Barnett J. Suctioning: A review of current research recommendations. Intensive and Crit Care Nurs 2002;18:79-89.

15. Van de Leur JP, Zwaveling JH, Loef BG, van der Schans CP. Endotracheal suctioning versus minimally invasive airway suctioning in intubated patients: A prospective randomised controlled trial. Intensive Care Med 2003;29:426-32.

16. Garstang SV, Kirshblum NC, Wood KE. Patient preference for in-exsufflator for secretion management with spinal cord injury. J Spinal Cord Med 2000;23:80-5.

17. Sancho J, Servera E, Vergara P, et al. Mechanical insufflationexsufflation vs. tracheal suctioning via tracheostomy tubes for patients with amyotrophic lateral sclerosis: A pilot study. Am J Phys Med Rehabil 2003;82:750-3.

18. Pillastrini P, Bordini S, Bazzocchi G, et al. Study of the effectiveness of bronchial clearance in subjects with upper spinal cord injuries: Examination of a rehabilitation programme involving mechanical insufflation and exsufflation. Spinal Cord 2006;44:614-6.

19. Make B, Hill N, Goldberg A, et al. Mechanical ventilation beyond the intensive care unit; Report of a consensus conference of the American College of Chest Physicians. Chest 1998;113:289-344.

20. Dhand R, Johnson JC. Care of the chronic tracheostomy. Respir Care 2006;51:984-1001.

21. Bach JR, Goncalves M. Ventilator weaning by lung expansion and decannulation. Am J Phys Med Rehabil 2004;83:560-8.

\section{SECTION II. TRANSITION TO HOME (PATIENTS ADMITTED TO HOSPITAL)}

\section{Introduction}

Although chronic respiratory failure and the consequent need for long-term ventilatory support can result from a variety of diagnoses, in all cases, there are constants to be addressed when transitioning to home (1). There are both medical and nonmedical factors that determine the suitability of a VAI to go home on ventilatory support (2-8). A comprehensive assessment must be performed by an interdisciplinary health care team to provide the necessary training to make a successful transition to home - ideally with a rehabilitative approach $(4,9)$.

\section{Key evidence}

Prospective observational studies and retrospective reviews based on small numbers of patients comprise the evidence base for the recommendations on the transition to home (10-12). The strength of the recommendations informing this section is primarily based on the consensus of the HMV committee. Current publications address different aspects of the factors influencing successful transition of VAIs to home. Randomized control studies in this topic are unlikely to be conducted.

\section{Conclusion}

The transition to home is a complex and demanding process for VAIs, and require highly sophisticated technology. Effective initiation and optimal monitoring of treatment are essential elements of successful HMV. The HMV committee recommends that an interdisciplinary team of health care professionals is of utmost importance for successful transition to home - provided that decisions are made under the leadership of a physician who is experienced in long-term ventilation. Commitment, motivation and preparation from patients' families and caregivers are also crucial for a successful transition to HMV. Family preparation is especially important in the establishment of care at home for VAIs who are not fully independent.

Prospective users of HMV need to be advised that acquiring equipment, learning how to use it and preparing the home environment can take a significant amount of time. Furthermore, the needs of the patient, family, caregivers and the home health care team must each be taken into consideration during this initial process. The interface of the VAI and the ventilator (invasive or noninvasive), for example, will greatly influence the complexity of individual care plans (13-15).

Many VAIs do not have the level of personal or third-party insurance to cover the initial costs of the ventilator and associated respiratory equipment. In addition, if the equipment malfunctions or fails, they may not have the resources to repair or obtain replacement in a timely fashion, thus increasing the likelihood of a return to hospital. Therefore, it is strongly suggested that a publicly funded system to support VAIs in the community be available and include timely access to equipment, maintenance services and a structured, ongoing educational program. Such a program is also expected to facilitate the transition to home, thus reducing hospital days.

\section{SECTION II. RECOMMENDATIONS}

1. The candidate should be medically stable without constant or frequent monitoring, tests or treatment changes. (Consensus)

2. The candidate and family must be motivated (Consensus):

- VAIs must express interest in transitioning/living in the community.

- The family should express commitment to having the VAI live in the community.

- The family is willing to provide support (physical, emotional and financial).

3. The candidate must have an adequate home setting (Consensus):

- Identifiable home to live in, suitable to the needs of the VAI.

- Home is adaptable as necessary.

4. The candidate must have sufficient caregiver support (Consensus):

- Caregivers identified and committed to provide sufficient hours of care to meet the needs of the VAI.

- Available government-funded care hours identified.

5. The candidate must have access to adequate financial resources (Consensus):

- Sources of financial assistance identified and accessed.

- Sufficient financial resources available to meet projected costs.

6. The candidate must have access to equipment appropriate for the needs (Consensus):

- Appropriate equipment selected and ordered.

- Sources for ongoing supplies identified. 
7. There must be comprehensive initial training, plus ongoing education and training for patient and caregivers once they are in the home setting (Consensus):

- Initial education organized to accommodate learning, practice and inclusion of caregivers in the care routine as early as possible.

8. The candidate must have access to health care support in the community (Consensus):

- Follow-up care available as appropriate (tracheotomy tube changes, ventilator reassessments and assessment of the ongoing effectiveness of the ventilatory support).

- Medical follow-up to allow for appropriate changes to the mode of ventilation (ie, from invasive to noninvasive and vice versa, from continuous to nocturnal and vice versa).

- Professional services available postdischarge.

- A government-funded ventilatory service is necessary to provide appropriate access to equipment and respiratory care.

\section{REFERENCES}

1. Warren M, Jarrett C, Senegal R, et al. An interdisciplinary approach to transitioning ventilator-dependent patients to home. J Nurs Care Qual 2004;19:67-73.

2. Jankey S, Donner CF. Psychological aspects in patients with chronic respiratory failure. In: Ambrosino N, Goldstein R, eds. Ventilatory Support for Chronic Respiratory Failure. Lung Biology in Health and Disease. New York: Informa Healthcare, 2008:225.

3. Van Kesteren RG, Velthuis B, Van Leyden LW. Psychosocial problems arising from home ventilation. Am J Phys Med Rehab 2001;80:439-46.

4. Moss AH, Casey P, Stocking CB, et al. Home ventilation for amyotrophic lateral sclerosis patients: Outcomes, costs and patient, family and physician attitudes. Neurology 1993;43:438-43.

5. Vitacca M, Escarrabil J, Galavotti G, et al. Home mechanical ventilation patients: A retrospective survey to identify level of burden in real life. Monaldi Arch Chest Dis 2007;67:142-7.

6. Tsara V, Serasli E, Voutsas V, et al. Burden and coping strategies in families of patients under non-invasive home mechanical ventilation. Respiration 2006;73:61-7.

7. Marchese S, Lo Coco D, Lo Coco A. Outcomes and attitudes towards home tracheostomy ventilation of consecutive patients: A 10 year experience. Respir Med 2008;102:430-6.

8. Lindahl B, Sandman P-O, Rasmussen BH. Meaning of living at home on a ventilator. Nursing Inquiry 2003;10:19-27.

9. Thomas DC, Kreizman IJ, Mekhiarre P, et al. Rehabilitation of the patient with chronic critical illness. Crit Care Clinic 2002;18:695-715.

10. Avendaño M, Goldstein RS, Güell R. Lung Biology in Health and Disease. Long Term Mechanical Ventilation. Rehabilitation of long term mechanically ventilated patients. In: C Lenfant, $\mathrm{N}$ Hill, eds. New York: Informa Healthcare, 2000:449-70.

11. Wagner EH. The role of patient care teams in chronic disease management. BMJ 2000;320:569-71.

12. Brooks D, Gibson B, De Matteo D. Perspectives of personal support workers and ventilator-users on training needs.

Patient Educ Couns 2008;71:244-50.

13. Oberwaldner B, Eber E. Tracheostomy care in the home. Pediatr Respir Rev 2006;7:185-90.

14. Long-Term Ventilation Centre of Excellence. Home Ventilation Training Program. West Park Healthcare Centre. Toronto: Long-Term Ventilation Centre of Excellence, 2008.

15. Vitacca M, Assoni G, Pizzocaro P, et al. A pilot study of nurse-led home monitoring for patients with chronic respiratory failure and with mechanical assistance. J Telemed Telecare 2006;12:337-42.

\section{SECTION III. HMV FOR PATIENTS WITH ALS \\ Introduction}

ALS is a neurodegenerative disorder involving both upper and lower motor neurons that results in the progressive weakness of skeletal muscles. Death usually occurs as a result of progressive respiratory muscle involvement, with $50 \%$ of patients dying within three years of symptom onset (1). The rapid progression to death separates ALS from most other NMDs for which NIV and tracheostomy ventilation is considered. ALS is also distinct from other ventilated medical conditions, including other NMDs, by virtue of having the poorest survival on ventilation (2). As a result, authors have tried to address the question of benefit of NIV in this disease.

In reviewing the evidence, consideration was given to the type and magnitude of benefit of NIV in ALS, monitoring required in this population, and timing or parameters for initiation of ventilation to obtain any significant benefit. The committee also attempted to find evidence for the specific manner in which ventilation should be performed in this population.

\section{Key evidence}

Compared with other disease groups, there is a relatively large volume of literature that attempts to answer the questions posed above. However, despite suggesting benefit for ventilation in ALS, the available information is not definitive and is of low quality in many instances. There is only a single RCT, and the remainder of the literature consists of prospective and retrospective studies or series. Control groups are present in many of the prospective studies; however, they often consist of historical controls, patients declining or unable to tolerate treatment, or patients with similar disease severity without respiratory involvement.

One small RCT (3), nine prospective studies (4-12) and six retrospective reviews (13-18) inform the question of benefit of home NIV or timing of initiation of NIV in patients with ALS. In these studies, outcomes of interest included survival, health-related QoL (HRQoL), pulmonary function, gas exchange, sleep parameters, cognition and timing of initiation of NIV.

One RCT (3), four prospective studies $(4,5,8,12)$ and three retrospective reviews $(15-17)$ informed the question of survival benefit with NIV. They all reported a survival benefit; however, the magnitude of the survival benefit was modest. Subset analysis of the bulbarpredominant patients in the RCT (3) did not show a survival benefit in the patients with severe bulbar dysfunction.

Seven studies, including the single RCT, reported QoL measures $(3,4,6,7-10)$. All showed improvement in QoL in some domains, with these improvements persisting in spite of disease progression. The improvement in QoL was still found in the more severe bulbar population in the RCT, although gains were not as significant (3). Another study examined cognitive function before and after ventilation (6), and showed improvement following initiation of NIV that was assumed to be secondary to treatment of sleep disordered breathing.

Some studies identified other benefits, including a slowing of decline in $\mathrm{VC}(10,12,16)$ and improved arterial blood gases (ABGs) $(6,9,19)$ following initiation of ventilation. Indications for the initiation of ventilation in studies showing benefit have not been consistent, making it difficult to answer the questions of how to monitor patients and when to initiate ventilation. Earlier literature focused on measures of lung function that predict daytime hypercapnia or a short time to death because these were frequently used criteria to initiate mechanical ventilation. More recently, the focus has been on predicting nocturnal hypoventilation to initiate ventilation earlier. A sitting VC of $<50 \%$ of predicted was recognized as a prognostic factor predicting death in less than six to nine months (20-22). Sniff nasal pressure (SNP), a noninvasive measure of respiratory muscle strength, was shown to better predict daytime hypercapnia than $\mathrm{VC}$ and maximal inspiratory pressure (MIP) (23), and can be performed more reliably than MIP in advanced disease, particularly when there is bulbar weakness. Bulbar weakness often leads to difficulty in maintaining an adequate oral seal and, hence, obtaining reliable measurements. An SNP of $<40 \mathrm{~cm}$ was also found to correlate with nocturnal hypoxemia and a median survival of six months (24). MIP is also a sensitive test of muscle function and can be used late in the disease to predict survival, although it also requires the patient to be able to form a seal around a mouthpiece for reliable measurements. A reduction in $\mathrm{VC}$ on assuming 
the supine position is frequently associated with the symptom of orthopnea (25), and the percentage drop correlates with the lowest saturation in rapid eye movement sleep (26). One author found a Borg dyspnea scale of $\geq 3$ on assuming the supine position a useful predictor of an SNP $\leq 40$ and impending respiratory failure (27). Symptom improvement was reported in four studies in which documented sleep disordered breathing was treated with NIV $(17,20,28,29)$. Orthopnea is a frequent indication for initiation of ventilation in the studies reported $(4,5,8,10,13,15)$. One study $(10)$ showed that the greatest benefit and adherence occurred in patients who complained of orthopnea. The same study suggested that patients treated for asymptomatic nocturnal hypoventilation were less compliant, although the numbers were very small.

Evidence is lacking to inform the questions of where ventilation should be initiated and how the initial and subsequent ventilator settings should be chosen. Only eight of the 16 studies informing the question of benefit of NIV described how the ventilator settings were determined. In spite of demonstrating successful treatment, only one study (17) used polysomnography to determine settings, and only three studies $(3,10,13)$ used nocturnal oximetry to evaluate settings after initiation. Seven of the eight studies that described methods for setting the initial ventilation $(3,5,8-10,12,13)$ reported adjusting the ventilation to patient comfort and symptoms. Not all authors reported the type of bilevel parameter used (spontaneous versus spontaneous/ timed $[S / T]$ ). Of those reporting, however, all reported the S/T mode with which a back-up rate is provided. The remainder of the studies that did not use bilevel pressure ventilation used volume-cycled ventilation, which requires specification of a respiratory rate. Because central apneas and hypoventilation figure prominently in previous descriptions of sleep disordered breathing in patients with ALS $(17,20,28-32)$, a backup rate would be recommended if bilevel ventilation is used.

Tracheostomy ventilation is an option if prolonged survival is desired and cannot be achieved with NIV. In a recent Canadian survey of ventilatory practices in ALS (33), it was estimated that only $1.5 \%$ of ALS patients receive this type of ventilation. Tracheostomy ventilation is associated with a high burden of care and, although chosen by some, tracheostomy may result from an acute deterioration and intubation when a personal directive is unavailable.

Following tracheostomy for acute respiratory failure, a recent Italian study (34) reported that none of the patients died in hospital; however, $70 \%$ were discharged completely ventilator dependent, and $28 \%$ partially ventilator dependent. Only one patient was liberated from mechanical ventilation. None of the patients had their tracheostomy removed. Bach (16) and Bach et al (35) described decannulation after tracheostomy in a select group of ALS patients with preserved bulbar function and the ability to generate an assisted PCF of $>160 \mathrm{~L} / \mathrm{min}$. Despite these occasional reports and the possibility of an extended period of NIV after decannulation, tracheostomy will be required in the future because bulbar function deteriorates if patients choose invasive ventilation in the hope of prolonged survival.

Since 2007, diaphragm pacing has been reported in 38 patients with ALS (36), and there is an ongoing trial targeting this therapy in 100 ALS patients. The initial goal with this therapy was to reduce the rate of decline in lung function. The laparoscopic insertion of the electrodes into the diaphragm in patients with a forced vital capacity (FVC) of $>50 \%$ predicted has been shown to be safe, with no mortality and low morbidity (37). Applied positive airway pressure (PAP) may still be required during pacing to avoid upper airway collapse. In the small number of ALS patients reported to date, there may be a slower rate of decline in lung function, which was extrapolated to a longer ventilator-free survival rate. Report of the larger series of ALS patients is pending; however, this technology is not yet approved for ALS patients in Canada.

The importance of airway clearance is highlighted in Section I (Airway Clearance). There have been studies conducted specifically in the ALS population, however, that warrant mention. One study investigated predictors of ineffective cough during chest infections in patients with stable ALS (38). They found that a Norris bulbar scale of $<29$ (normal function 39), PCF $<4.25 \mathrm{~L} / \mathrm{s}$ in stable ALS patients predicted ineffective cough with a chest infection and, therefore, suggested that assisted clearance techniques be introduced when patients reach one or more of these thresholds. Another study in ALS patients (39) showed that PCF could be dramatically increased with various assisted-cough techniques, even in patients with bulbar dysfunction, a group in whom it has been challenging to achieve good clearance of airway mucus. Finally, a study assessing the efficacy of MI-E in stable ALS patients (40) also found that this technique could generate clinically effective PCF in all patients but those with very severe bulbar dysfunction.

\section{Conclusion}

The majority of the studies investigating outcomes of NIV use have been observational cohort studies, with only a single RCT to date. Although the evidence base is modest, it is relatively consistent in favour of benefit to patients able to tolerate NIV. In ALS patients, the survival benefit is modest compared with other diagnoses for which HMV is commonly recommended. The improvement in QoL, including improvements in measures of daytime fatigue and sleepiness, seems to be a more relevant end point in this patient population. Sustained improvements in QoL were seen in most studies. Most importantly, there was no deterioration in QoL with NIV use apart from the expected changes in domains related to physical functioning secondary to increasing disability. Initiation of ventilation for symptomatic daytime hypercapnia or orthopnea secondary to muscle weakness seems clear. Earlier initiation for nocturnal hypoventilation with normal daytime $\mathrm{PCO}_{2}$ or based on higher FVC may be of benefit, but the evidence to date is limited.

\section{SECTION III. RECOMMENDATIONS}

1. Regular monitoring of ALS patients is advised from the time of diagnosis every two to six months and varies with anticipated rapidity of disease progression and should include the following:

- Symptom review to include orthopnea, dyspnea, poor sleep, excessive daytime sleepiness, poor concentration, morning headache. (Grade of recommendation 1C)

- Measurement of sitting FVC. (Grade of recommendation 1C)

- Measurement of one or more of the following: supine VC, SNP, PI ${ }_{\max }$ (MIP). (Grade of recommendation 1C)

- Measurement of $\mathrm{ABG}$ or end tidal $\mathrm{CO}_{2}\left(\mathrm{ETCO}_{2}\right)$ when hypercapnia is suspected. (Grade of recommendation 1C)

- Nocturnal oximetry \pm transcutaneous $\mathrm{CO}_{2}\left(\mathrm{tCO}_{2}\right)$ when symptomatic sleep disordered breathing is suspected. (Grade of recommendation 2C)

- Measurement of PCF. (Grade of recommendation 1C)

2. NIV should be offered to patients with any one of the following:

- Orthopnea (Grade of recommendation 1B)

- Daytime hypercapnia (Grade of recommendation 1B)

- Symptomatic sleep disordered breathing (Grade of recommendation $1 \mathrm{C})$

- $\mathrm{FVC}<50 \%$ predicted (Grade of recommendation 1C)

- $\mathrm{SNP}<40 \mathrm{cmH}_{2} \mathrm{O}$ or $\mathrm{PI}_{\max }<40 \mathrm{cmH}_{2} \mathrm{O}$ (Grade of recommendation $1 \mathrm{C}$ ).

3. Ventilator settings should be adjusted for optimal patient comfort and improvement of symptoms. ABGs and/or nocturnal oximetry and/or polysomnography are not required, but may be helpful in some circumstances. (Grade of recommendation $1 \mathrm{C}$ ) 
4. When bilevel pressure ventilators are used for NIV, a backup rate is recommended. (Grade of recommendation 1C)

5. Indicators of the effectiveness of ventilatory support should include symptom resolution, overnight oximetry and/or $\mathrm{ETCO}_{2}$. (Grade of recommendation 1C)

6. NIV should be considered the preferred option for ventilation even when ventilation is required $24 \mathrm{~h}$ per day. Elective tracheostomy ventilation may be considered, and is dependent on regional resources and careful discussion with the patient and caregivers. (Grade of recommendation 1C)

7. Long-term invasive ventilation can be offered after acute respiratory failure requiring invasive ventilation, if the patient and caregivers fully understand the consequences and appropriate support is available (Section II. Transition to Home). (Grade of recommendation 2C)

8. Lung volume recruitment manoeuvres should be introduced with declining VC (Section I. Airway Clearance). (Grade of recommendation $1 \mathrm{C}$ )

9. Methods to assist secretion clearance should be initiated when PCF is $<4.25 \mathrm{~L} / \mathrm{s}$ or the Norris bulbar score is $<29$. (Grade of recommendation $1 \mathrm{C}$ )

\section{REFERENCES}

1. Haverkamp LJ, Appel V, Appel SH. Natural history of amyotrophic lateral sclerosis in a database population. Validation of a scoring system and a model for survival prediction. Brain $1995 ; 18: 707-19$.

2. Laub M, Midgren B. Survival of patients on home mechanical ventilation: A nationwide prospective study. Respir Med 2007;101:1074-8.

3. Bourke SC, Tomlinson M, Williams TL, Bullock RE, Shaw PJ, Gibson GJ. Effects of non-invasive ventilation on survival and quality of life in patients with amyotrophic lateral sclerosis: A randomized controlled trial. Lancet Neurol 2006;5:140-7.

4. Pinto AC, Evangelista T, Carvalho M, Alves MA, Sales Luis ML. Respiratory assistance with a non-invasive ventilator (Bipap) in MND/ALS patients: Survival rates in a controlled trial. J Neurol Sci 1995;129(Suppl):19-26.

5. Aboussouan LS, Khan SU, Meeker DP, Stelmach K, Mitsumoto H. Effect of non-invasive positive-pressure ventilation on survival in amyotrophic lateral sclerosis. Ann Intern Med 1997;127:450-3.

6. Newsom-Davis IC, Lyall RA, Leigh PN, Moxham J, Goldstein LH. The effect of non-invasive positive pressure ventilation on cognitive function in amyotrophic lateral sclerosis (ALS): A prospective study. J Neurol Neurosurg Psychiatry 2001;71:482-7.

7. Jackson CE, Rosenfeld J, Moore DH, et al. A preliminary evaluation of a prospective study of pulmonary function studies and symptoms of hypoventilation in ALS/MND patients. J Neurol Sci 2001;191:75-8.

8. Aboussouan LS, Khan SU, Banerjee M, Arroliga AC, Mitsumoto H. Objective measures of the efficacy of non-invasive positive pressure ventilation in amyotrophic lateral sclerosis. Muscle Nerve 2001;24:403-9.

9. Lyall RA, Donaldson N, Fleming T, et al. A prospective study of quality of life in ALS patients treated with non-invasive ventilation. Neurology 2001;57:153-6.

10. Bourke SC, Bullock RE, Williams TL, Shaw PJ, Gibson GJ. Non-invasive ventilation in ALS: Indications and effect on quality of life. Neurology 2003;61:171-7.

11. Pinto A, de Carvalho M, Evangelista T, Lopes A, Sales-Luis L. Nocturnal pulse oximetry: A new approach to establish the appropriate time for non-invasive ventilation in ALS patients. Amyotroph Lateral Scler Other Motor Neuron Disord 2003:4:31-5.

12. Lo Coco D, Marchese S, Pesco MC, La Bella V, Piccoli F, Lo Coco A. Non-invasive positive-pressure ventilation in ALS: Predictors of tolerance and survival. Neurology 2006;67:761-5.

13. Ferraro E, Prats E, Povedano M, Marinez-Matos, Manresa F, Escarrabill J. Survival in ALS with home mechanical ventilation. The impact of systematic respiratory assessment and bulbar involvement. Chest 2005;127:2132-8.
14. David WS, Bundlie SR, Mahdavi Z. Polysomnographic studies in amyotrophic lateral sclerosis. J Neuro Sci 1997;152(Suppl):S29-35.

15. Kleopa KA, Sherman M, Neal B, Romano GJ, Heiman-Patterson T. Bipap improves survival and rate of pulmonary function decline in patients with ALS. J Neurol Sci 1999;164:82-8.

16. Bach JR. Amyotrophic lateral sclerosis: Prolongation of life by non-invasive respiratory AIDS. Chest 2002;122:92-8.

17. Berlowitz DJ, Detering K, Schachter L. A retrospective analysis of sleep quality and survival with domiciliary ventilator support in motor neuron disease. Amyotroph Lateral Scler 2006; 7:100-6.

18. Lechtizin N, Scott Y, Busse AM, Clawson LL, Kimball R, Wiener CM. Early use of non-invasive ventilation prolongs survival in subjects with ALS. Amyotroph Lateral Scler 2007;8:185-8.

19. David WS, Bundlie SR, Mahdavi Z. Polysomnographic studies in amyotrophic lateral sclerosis. J Neuro Sci 1997;152(Suppl):S29-35.

20. Fallat RJ, Jewitt B, Bass M, Kamm B, Norris FH. Spirometry in Amyotroph Lateral Scler Arch Neurol 1979;36:74-80.

21. Stamber N, Charatan M, Cedarbaum JM. Prognostic indicators of survival in ALS. ALS CNTF Treatment Study Group. Neurology 1998;50:66-72.

22. Czaplinski A, Yen AA, Appel SH. Forced Vital Capacity (FVC) as an indicator of survival and disease progression in an ALS clinic population. J Neurol Neurosurg Psychiatry 2006;77:390-2.

23. Lyall FA, Donaldson N, Polkey MI, Leigh PN, Moxham J. Respiratory muscle strength and ventilator failure in amyotrophic lateral sclerosis. Brain 2001;124:2000-13.

24. Morgan RK, McNally S, Alexander M, Conroy R, Hardiman O, Costello RW. Use of Sniff nasal-inspiratory force to predict survival in amyotrophic lateral sclerosis. Am J Respir Crit Care Med 2005;171:269-74.

25. Varrato J, Siderowf A, Damiano P, Gregory S, Feinberg D, McCluskey L. Postural change of forced vital capacity predicts some respiratory muscle symptoms in ALS. Neurology 2001;57:357-9.

26. Bye PT, Ellis ER, Issa FG, Donnelly PM, Sullivan CE. Respiratory failure and sleep in neuromuscular disease. Thorax 1990;45:241-7.

27. Just N, Bautin N, Danel-Brunaud V, Debroucker V, Matran R, Perez T. The Borg dyspnea score: A relevant clinical marker of inspiratory muscle weakness in amyotrophic lateral sclerosis. Eur Respir J 2010;35:353-60

28. Gay PC,Westbrook PR, Daube JR, Litchy WJ, Windebank AJ, Iverson R. Effects of alterations in pulmonary function and sleep variables on survival in patients with amyotrophic lateral sclerosis. Mayo Clin Proc 1991;66:686-94.

29. Ferguson KA, Strong MJ, Ahmad D, George CFP. Sleep disordered breathing in amyotrophic lateral sclerosis. Chest 1996;110:664-9.

30. Kimura K, Tachibana N, Kimura J, Shibasadi H. Sleep-disordered breathing at an early stage of amyotrophic lateral sclerosis. J Neurol Sci 1999;164:37-43.

31. Arnulf I, Similowski T, Salachas F, et al. Sleep disorders and diaphragm function in patients with amyotrophic lateral sclerosis. Am J Respir Crit Care Med 2000;161:849-56.

32. Atalaia A, De Carvalho M, Evengelista T, Pinto A. Sleep characteristics of amyotrophic lateral sclerosis in patients with preserved diaphragmatic function. Amyotroph Lateral Scler 2007;8:101-5.

33. Ritsma BR, Berger MJ, Charland DA, et al. NIPPV: Prevalence, approach and barriers to use at Canadian ALS centres. Can J Neurol Sci 2010;37:54-60.

34. Vianello A, Arcaro G, Palmeiri A, et al. Survival and quality of life after tracheostomy for acute respiratory failure in patients with amyotrophic lateral sclerosis. J Crit Care 2011;26:329.e7-329.e14.

35. Bach JR, Goncalves MR, Hamdani I, Winck JC. Extubation of patients with neuromuscular weakness: A new management paradigm. Chest 2010;137:1033-9.

36. Onders RP, Elmo M, Khansarinia S, et al. Complete worldwide operative experience in laparoscopic diaphragm pacing: Results and differences in spinal cord injured patients and amyotrophic lateral sclerosis patients. Surg Endosc 2009;23:1433-40.

37. Onders RP, Carlin AM, Elmo M, Sivashandaran S, Katirji B, Schilz R. Amyotrophic lateral sclerosis: The Midwestern surgical experience with the diaphragm pacing stimulation system shows that general anesthesia can be safely performed. Am J Surg 2009;197:386-90. 
38. Sancho J, Servera E, Diaz J, Marin J. Predictors of ineffective cough during a chest infection in patients with stable amyotrophic lateral sclerosis. Am J Respir Crit Care Med 2007;175:1266-71.

39. Senent C, Golmard J-L, Salachas F, et al. A comparison of assisted cough techniques in stable patients with severe respiratory insufficiency due to amyotrophic lateral sclerosis. Amyotroph Lateral Scler 2011;12:26-32.

40. Sancho J, Servera E, Diaz J, Marin J. Efficacy of mechanical insufflation-exsufflation in medically stable patients with amyotrophic lateral sclerosis. Chest 2004;125:1400-5.

\section{SECTION IV. HMV FOR PATIENTS WITH CHS}

\section{Introduction}

Patients with CHS present with varying degrees of severity. Patients are known to have normal lung function and respiratory muscle strength. The problem resides in the development of adequate neural drive from the central nervous system, to maintain a normal $\mathrm{PCO}_{2}$. Severe congenitalCHS (C-CHS) presents at birth with profound hypoventilation that requires continuous invasive ventilatory support. Alternatively, adults presenting in later life, for example with late-onset CHS (LO-CHS) or an acquired form of CHS, may only have nocturnal hypercapnia. Eventually, these patients tend to progress to diurnal hypercapnia with daytime symptoms. These daytime symptoms commonly include morning headaches, sleepiness and confusion, and dictate the need for nocturnal ventilatory support. CHS can be acquired due to brainstem disease, for example, or from a stroke or tumour. When brainstem disease is excluded by magnetic resonance imaging, genetic analysis is indicated $(1,2)$. The presence of a mutation in the PHOX2B gene is identified in most cases and confirms the genetic nature of this condition. The mode of inheritance is autosomal dominant. This mutation is usually a polyalanine expansion that causes more severe hypoventilation as the expansion lengthens. Firstdegree relatives of affected individuals should be offered genetic testing and screened for hypoventilation because they may also carry the mutation and should be counselled appropriately.

\section{Key evidence}

The literature search revealed 10 articles reporting on the management of CHS patients. The experience reported is largely based on case series with a focus on C-CHS (3-8). Due to the rarity of CHS, there is little evidence to support an optimal approach to management; thus, recommendations informing this section are primarily based on consensus of the HMV committee and a recent American Thoracic Society statement on C-CHS (9).

\section{Conclusion}

In the adult population, there are little data regarding long-term follow-up, with most reports focusing on describing the causes of acquired CHS. In this setting, nocturnal NIV is often all that is required. In the pediatric population, C-CHS can be quite profound at birth, requiring continuous invasive ventilatory support; however, as the child matures, breathing may require support at night only $(7,8,10)$. The options for ventilatory support include positive pressure ventilation (PPV) via tracheostomy, NIV or diaphragm pacing $(10,11,12)$. There is a preference for NIV or diaphragm pacing as the child matures, with the aim of decannulation. In the less common situation in which $24 \mathrm{~h}$ ventilation is required, diaphragm pacing allows for increased mobility during the day and, in some cases, NIV can suffice at night with the potential for decannulation. Alternatively, NIV may be adequate for $24 \mathrm{~h}$ ventilatory support when the patient is at the age to be capable of adopting it. Transition clinics for children are important in providing a care plan, particularly for the more complicated patients with C-CHS as they move into adulthood.

\section{SECTION IV. RECOMMENDATIONS}

1. The diagnosis of CHS in adults with less severe hypoventilation is best made by standard polysomnography with the addition of $\mathrm{tCO}_{2}$ or early morning arterial $\mathrm{PCO}_{2}$. (Grade of recommendation 1C)
2. Once the diagnosis of CHS is established, it is strongly recommended that acquired causes should be excluded by magnetic resonance imaging of the brainstem. (Grade of recommendation $1 \mathrm{C}$ )

3. Patients with CHS and no known acquired cause should undergo genetic screening for the $\mathrm{PHOX} 2 \mathrm{~B}$ gene mutation. (Grade of recommendation 1C)

4. For patients confirmed to harbour the PHOX2B mutation, firstdegree relatives should be offered genetic testing and screening for hypoventilation. (Grade of recommendation 1C)

5. CHS patients who require only nocturnal ventilatory support may be managed by NIV with a backup rate or diaphragmatic pacing. (Grade of recommendation 1C)

6. Severe CHS, mainly seen in C-CHS, requires continuous invasive ventilatory support, but daytime diaphragmatic pacing can markedly improve mobility and, as the child matures, NIV may suffice. (Grade of recommendation 1C)

\section{REFERENCES}

1. Amiel J, Laudier B, Attie-Bitach T, et al. Polyalanine expansion and frameshift mutations of the paired-liked homeobox gene PHOX2B in congenital central hypoventilation syndrome. Nat Genet 2003;33:439-61.

2. Trochet D, de Pontual L, Straus C, et al. PHOX2B germline and somatic mutations in late-onset central hypoventilation syndrome. Am J Respir Crit Care Med 2008;177:906-11.

3. Trang H, Dehan M, Beaufils F, et al. The French congenital central hypoventilation syndrome registry. Chest 2005;127:72-9.

4. Oren J, Kelly H, Shannon DC. Long-term follow-up of children with congenital central hypoventilation syndrome. Pediatrics 1987;80:375-80.

5. Marcus CL, Mansen MT, Poulsen MK, et al. Medical and psychosocial outcome of children with congenital central hypoventilation syndrome. J Pediatr 1991;119:888-95.

6. Vanderlaan M, Holbrook CR, Wang M, et al. Epidemiologic survey of 196 patients with congenital central hypoventilation. Pediatr Pulmonol 2004;37:217-29.

7. Weese-Mayer DE, Silvestri JM, Menzies LJ, et al. Congenital central hypoventilation syndrome: Diagnosis, management, and long-term outcome in thirty-two children. J Pediatr 1992;120:381-7.

8. Tibballs J, Henning RD. Non-invasive ventilatory strategies in the management of a newborn infant and three children with congenital central hypoventilation syndrome. Pediatr Pulmonol 2003;36:544-8.

9. Weese-Mayer DE, Berry-Kravis EM, Ceccherini I, et al. An official ATS clinical policy statement: Congenital central hypoventilation syndrome. Am J Respir Crit Care Med 2010;181:626-44.

10. Glenn WWL, Gee JB, Cole DR, et al. Combined central alveolar hypoventilation and upper airway obstruction: Treatment by tracheostomy and diaphragm pacing. Am J Med 1978;64:50-60.

11. Moxham J, Shneerson JM. Diaphragmatic pacing. Am Rev Respir Dis 1993;148:533-6.

12. Onders RP, Elmo MJ, Ignagni AR. Diaphragm pacing stimulation system for tetraplegia in individuals injured during childhood or adolescence. J Spinal Cord Med 2007;30(Suppl 1):S25-9.

\section{SECTION V. LONG-TERM NONINVASIVE PPV IN PATIENTS WITH STABLE COPD}

In this section, noninvasive PPV (NIPPV) will replace 'NIV' because the term is commonly used in the COPD population.

\section{Introduction}

The goal of COPD treatment is to slow disease progression, reduce the frequency of exacerbations, alleviate dyspnea, improve exercise tolerance, improve health status and reduce mortality (1). Although several physiological outcomes such as ABGs, work of breathing and respiratory muscle strength can be improved by long-term mechanical ventilation, the clinical relevance of these outcomes from the perspective of the patient and/or health care system is uncertain. Recommendations for the use of NIPPV in COPD will thus be based on the results of clinical trials that have assessed the impact of NIPPV on patient-oriented clinical outcomes. 


\section{Key evidence}

Seven RCTs (2-8) comprise the evidence base regarding the role of long-term NIPPV in patients with stable COPD. Recommendations informing this section are based on evidence from these RCTs and the consensus of the HMV expert panel.

Conducting a clinical trial investigating the efficacy of long-term NIPPV in patients with COPD is challenging. By definition, patients involved in these trials suffer from advanced chronic respiratory failure and, in some instances, from preterminal disease. A high dropout rate and a multitude of adverse events are, therefore, expected during such a trial. One problem in trying to interpret the current literature is the heterogeneity of the study population and the difference in the degree of ventilatory support among studies. Studies were either very small (2-4) or the investigators were unable to meet the predefined sample size to ensure sufficient statistical power to address the outcomes of interest $(5,7,8)$.

Our interpretation is that the current literature does not support the use of NIPPV in stable patients with COPD with chronic hypercapnic respiratory failure. The dyspnea data are difficult to interpret considering the different dyspnea scales that were used in the different trials. In one study, the reduction in Borg dyspnea score was statistically significant and probably clinically significant, with a reduction in one unit occurring in the NIPPV group compared with no change in the control group (5). In another study (6), a 0.6 point difference in the Medical Research Council dyspnea score in favour of NIPPV was reported. The dyspnea data can probably be viewed as positive, although of modest magnitude and uncertain clinical importance. The impact of NIPPV on HRQoL data was assessed in four studies that reached different conclusions on this issue (3,6-8). Although NIPPV may improve HRQoL as assessed by St George's Respiratory Questionnaire (SGRQ) or by the Chronic Respiratory Questionnaire when associated with long-term oxygen therapy (LTOT) (3) or rehabilitation (7), the largest studies reported no improvement in SGRQ scores $(6,8)$. Using a questionnaire specifically designed to assess $\mathrm{QoL}$ in respiratory failure, evidence supporting improved $\mathrm{QoL}$ has been reported $(6,7)$. In contrast, one study suggested that QoL may deteriorate with NIPPV (8). However, the clinical interpretation of this questionnaire is uncertain. Overall, it is difficult to draw a clear conclusion on the impact of NIPPV on HRQoL from the published evidence.

The impact of NIPPV on exercise tolerance, as assessed by $6 \mathrm{~min}$ walk distance, and on sleep quality is inconclusive $(3,4,6)$. The initiation of long-term NIPPV in addition to oxygen, was not associated with a reduced risk of hospitalization during long-term follow-up (12 to 24 months) when compared with oxygen alone $(5,6)$. Finally, NIPPV did not prolong survival in two studies involving patients with stable COPD $(5,6)$. A survival advantage of NIPPV when used in conjunction with LTOT compared with LTOT alone has been reported (8). The biological plausibility of this study is questionable because the level of positive pressure applied was low and failed to improved daytime $\mathrm{PaCO}_{2}$.

Despite the limitations and the lack of clear supportive evidence, long-term NIPPV is widely used in patients with COPD. In some countries, COPD is one of the most rapidly rising indications for longterm ventilatory support (9). This is not trivial considering the large COPD population and the potential economic impact associated with long-term NIPPV in this population. Some experts would consider long-term NIPPV in patients with COPD and chronic hypercapnia experiencing repeated bouts of acute respiratory failure requiring ventilatory support in the hospital. The hope here is that this will reduce health care use (10). Given the lack of certainty about the efficacy of NIPPV in this patient population, isolated $\mathrm{PaCO}_{2}$ elevation is unlikely to represent a useful clinical indication (11).

Obesity, obstructive sleep apnea (OSA) and COPD are common medical conditions; their concomitant presence in the same individual is, therefore, not unusual. The coexistence of OSA and COPD is often coined the 'overlap syndrome' (12). Obesity and sleep apnea may lead to hypercapnic respiratory failure when associated with airflow obstruction. This situation should be suspected when the degree of airflow obstruction is milder (forced expiratory volume in $1 \mathrm{~s}$ $\left[\mathrm{FEV}_{1}\right]>40 \%$ predicted) than usually seen in a typical case of hypercapnic respiratory failure that is solely due to advanced COPD. The overlap syndrome should be differentiated from chronic hypercapnic respiratory failure due to advanced COPD because these two conditions may well require different treatment. NIPPV is often used in this setting and discussed in more detail in Section VII.

\section{Conclusion}

The current literature of RCTs does not provide convincing evidence that NIPPV is effective in improving patient-oriented clinical outcomes such as dyspnea, exercise tolerance, QoL, hospitalization and survival in COPD. Long-term NIPPV may be appropriate in carefully selected patients when COPD is accompanied by chronic hypercapnia and repeated bouts of acute respiratory failure requiring ventilatory support in the hospital, with the expectation that this will reduce health care use.

\section{SECTION V. RECOMMENDATIONS}

1. The use of long-term NIPPV cannot be widely recommended in patients with stable COPD. (Grade of recommendation 1B)

2. Long-term NIPPV in COPD should only be considered on an individual basis. One subgroup of patients with COPD in which long-term NIPPV could be considered are those with severe hypercapnia $\left(\mathrm{PaCO}_{2}>55 \mathrm{mmHg}\right)$ experiencing repeated episodes of acute hypercapnic respiratory failure that require in-hospital ventilatory support. However, definitive proof of efficacy of long-term NIPPV in these patients will need to await future studies. (Grade of recommendation 2C)

3. The overlap syndrome, and concomitant COPD and OSA syndrome, should be differentiated from chronic respiratory failure that is solely due to advanced COPD. (Grade of recommendation $1 \mathrm{C}$ )

\section{REFERENCES}

1. O'Donnell DE, Aaron S, Bourbeau J, et al. Canadian Thoracic Society recommendations for management of chronic obstructive pulmonary disease - 2007 update. Can Respir J 2007; (Suppl B):5B-32B.

2. Strumpf DA, Millman RP, Carlisle CC, et al. Nocturnal positivepressure ventilation via nasal mask in patients with severe chronic obstructive pulmonary disease. Am Rev Respir Dis 1991;144:1234-9.

3. Meecham Jones DJ, Paul EA, Jones PW, Wedzicha JA. Nasal pressure support ventilation plus oxygen compared with oxygen therapy alone in hypercapnic COPD. Am J Respir Crit Care Med 1995;152:538-44.

4. Gay PC, Hubmayr RD, Stroetz RW. Efficacy of nocturnal nasal ventilation in stable, severe chronic obstructive pulmonary disease during a 3-month controlled trial. Mayo Clin Proc 1996;71:533-42.

5. Casanova C, Celli BR, Tost L,et al. Long-term controlled trial of nocturnal nasal positive pressure ventilation in patients with severe COPD. Chest 2000;118:1582-90.

6. Clini E, Sturani C, Rossi A, et al. The Italian multi-centre study on non-invasive ventilation in chronic obstructive pulmonary disease patients. Eur Respir J 2002;20:529-38.

7. Duiverman ML, Wempe JB, Bladder G, et al. Nocturnal noninvasive ventilation in addition to rehabilitation in hypercapnic patients with COPD. Thorax 2008;63:1052-7.

8. McEvoy RD, Pierce RJ, Hillman D, et al. Nocturnal non-invasive nasal ventilation in stable hypercapnic COPD: A randomised controlled trial. Thorax 2009;64:561-6.

9. Lloyd-Owen SJ, Donaldson GC, Ambrosino N, et al. Patterns of home mechanical ventilation use in Europe: Results from the Eurovent survey. Eur Respir J 2005;25:1025-31.

10. Tuggey JM, Plant PK, Elliott MW. Domiciliary non-invasive ventilation for recurrent acidotic exacerbations of COPD: An economic analysis. Thorax 2003;58:867-71.

11. Cuvelier A, Molano LC, Muir JF. Ventilation à domicile chez les patients atteints de bronchopneumopathie chronique obstructive (BPCO). Rev Mal Respir 2005;22:615-33. 
12. Weitzenblum E, Chaouat A, Kessler R, Canuet M. Overlap syndrome: Obstructive sleep apnea in patients with chronic obstructive pulmonary disease. Proc Am Thorac Soc 2008;5:237-41.

\section{SECTION VI. HMV IN PATIENTS WITH KYPHOSCOLIOSIS}

\section{Introduction}

Kyphoscoliosis is a well-recognized cause of respiratory failure (1). The most common cause is idiopathic scoliosis, which begins in childhood. Kyphoscoliosis may also occur secondary to other disorders including NMD, vertebral disease, connective tissue abnormalities and thoracoplasty (2). The degree of thoracic spinal deformity is the most important risk factor for the eventual development of respiratory failure. Surgically untreated patients with a VC of $<45 \%$ of predicted values and a scoliotic angle $>110 \%$ are at particular risk of respiratory failure (3). This risk is elevated if NMD or coexistent lung disease is present. Once respiratory failure or corpulmonale develops, life expectancy with conservative therapy is poor. Up to $50 \%$ of untreated patients can be expected to die within one to two years without the initiation of oxygen or ventilatory support (1).

\section{Key evidence}

A total of 12 studies were identified informing the primary outcomes of interest on the role of HMV in patients with kyphoscoliosis (4-15). An additional study reporting on outcomes of NIV in post-tuberculosis patients with the combination of respiratory failure and chest wall deformity is relevant (16). Support for the use of NIV in kyphoscoliosis was initially established by the publication of several retrospective single cohort studies demonstrating improved survival compared with historical mortality (4-8). Subsequently, two large observational registries have directly compared survival between patients managed by LTOT or home ventilation (10-11), and both have demonstrated that home ventilation has a significant survival advantage. A smaller comparative study (12) also found similar results. Several smaller studies have confirmed earlier reports of improved gas exchange and indicate that home ventilation may improve some parameters of lung function, exercise endurance and $\mathrm{QoL}$ $(13-15)$. Recommendations informing this section are based on the limited evidence and the consensus of the HMV committee.

\section{Conclusion}

Evidence is lacking to support the initiation of NIV on the basis of pulmonary function alone - indeed, there are many factors that must be considered. Patients with kyphoscoliosis who present with a VC of $<50 \%$ predicted value can survive for many years before respiratory failure develops (3). Follow-up of patients presenting with acute hypoxic, hypercapnic respiratory failure caused by kyphoscoliosis has demonstrated that some patients can survive for years on oxygen therapy without ventilation (17). If oxygen therapy can relieve hypoxemia in patients with respiratory failure secondary to kyphoscoliosis without the development of hypercapnia, oxygen therapy alone can be considered; however, over time, monitoring for the development of $\mathrm{CO}_{2}$ retention is critical, and the addition of ventilatory support may be required (9). Most patients with established chronic hypercapnic respiratory failure caused by kyphoscoliosis should be offered nocturnal NIV (4-16).

\section{SECTION VI. RECOMMENDATIONS}

1. Patients with kyphoscoliosis should undergo periodical spirometry testing, and if $\mathrm{FVC}$ is $<50 \%$, ongoing review, assessing for evidence of hypercapnic respiratory failure should be instituted. (Grade of recommendation $1 \mathrm{C}$ )

2. Long-term nocturnal NIV should be offered to all patients with kyphoscoliosis who have developed chronic hypercapnic respiratory failure. (Grade of recommendation 1B)

3. Patients with hypoxemia but without hypercapnia may be managed cautiously with oxygen therapy alone while monitoring for development of hypercapnia. (Grade of recommendation 1C)

4. Oxygen therapy could be added to NIV, if considered necessary, for unresponsive oxygen desaturation. (Grade of recommendation 1C)
5. Methods to assist secretion clearance should be initiated when peak cough flow is $<270 \mathrm{~L} / \mathrm{min}$ (Section I. Airway Clearance) (Grade of recommendation $1 \mathrm{C}$ )

\section{REFERENCES}

1. Bergofsky E, Turino G, Fishman A. Cardiorespiratory failure in kyphoscoliosis. Medicine 1959;38:263-317.

2. Bradford D, Lonstein J, Moe J, Winter R. Moe's Textbook of Scoliosis and Other Spinal Deformities, 2nd edn. Philadelphia: WB Saunders \& Co, 1987.

3. Pehrsson K, Bake B, Larsson S, Nachemson A. Lung function in adult idiopathic scoliosis: A 20 year follow up. Thorax 1991;46:474-8.

4. Leger P, Bedicam J, Cornette A, et al. Nasal intermittent positive pressure ventilation. Chest 1994;105:100-5.

5. Simonds A, Elliot M. Outcome of domiciliary nasal intermittent positive pressure ventilation in restrictive and obstructive disorders. Thorax 1995;50:604-9.

6. Duiverman M, Bladder G, Meinesz, Wijkstra P. Home mechanical ventilatory support in patients with restrictive ventilatory disorders: A 48-year experience. Respir Med 2006;100:56-65.

7. Brooks D, De Rosie J, Mousseau M, Avendano M, Goldstein R. Long term follow-up of ventilated patients with thoracic restrictive or neuromuscular disease. Can Respir J 2002;9:99-106.

8. Baydur A, Layne E, Aral H, et al. Long term non-invasive ventilation in the community for patients with musculoskeletal disorders: 46 year experience and review. Thorax 2000;55:4-11.

9. Strom K, Pehrsson K, Boe J, Nachemson A. Survival of patients with severe thoracic spine deformities receiving domiciliary oxygen therapy. Chest 1992;102:164-8.

10. Chailleux E, Fauroux B, Binet F, Dautezenberg B, Polu J. Predictors of survival in patients receiving domiciliary oxygen therapy or mechanical ventilation - a 10-year analysis of ANTIDIR Observatory. Chest 1996;109:741-9.

11. Gustafson T, Franklin K, Midgrin B, Pehrsson K, Ranstam J, Strom K. Survival of patients with kyphoscoliosis receiving mechanical ventilation or oxygen at home. Chest 2006;130:1828-33.

12. Buyse B, Meersseman W, Demedts M. Treatment of chronic respiratory failure in kyphoscoliosis: Oxygen or ventilation. Eur Respir J 2003;22:525-8.

13. Gonzalez C, Ferris G, Diaz J, Fontana I, Nunez J, Marin J. Kyphoscoliotic ventilatory insufficiency-effects of long-term intermittent positive pressure ventilation. Chest 2003;124:857-62.

14. Schonhofer B, Wallstein S, Wiese C, Kohler D. Non-invasive mechanical ventilation improves endurance performance in patients with chronic respiratory failure due to thoracic restriction. Chest 2001;119:1371-8.

15. Nauffal D, Domenech R, Martinez Garcia M, Compte L, Macian V, Perpina M. Non-invasive positive pressure home ventilation in restrictive disorders: Outcome and impact on health related quality of life. Respir Med 2002;96:777-83.

16. Jager L, Franklin K, Midgren B, Lofdahl K, Strom K. Increased survival with mechanical ventilation in post tuberculosis patients with the combination of respiratory failure and chest wall deformity. Chest 2008;133:156-60.

17. Libby D, Briscoe W, Boyce B, Smith J. Acute respiratory failure in scoliosis and kyphoscoliosis; prolonged survival and treatment. Am J Med 1982;73:532-8.

\section{SECTION VII. HMV FOR PATIENTS WITH OHS}

\section{Introduction}

OHS is best characterized as daytime hypercapnia not due to respiratory or NMD, and accompanied by obesity and sleep disordered breathing

(1). For the purpose of this review, OHS is defined as follows:

1. Obesity (body mass index [BMI] $>30 \mathrm{~kg} / \mathrm{m}^{2}$ ).

2. Daytime hypercapnia $\left(\mathrm{PaCO}_{2}>45 \mathrm{mmHg}\right)$.

3. Absence of other causes of hypoventilation.

Sleep disordered breathing is very common among OHS patients, although not necessarily a part of the definition. Most OHS patients ( $80 \%$ to $90 \%$ ) also suffer from OSA, while hypoventilation without OSA and central apnea are less common (2).

The exact prevalence of OHS in the general population is not known. The prevalence of OHS in patients with OSA has been 
estimated to be between $20 \%$ and $30 \%$ (3). In a large French study of 1141 adults with OSA (4), daytime hypercapnia was present in $9.8 \%$ of patients with a BMI $>30 \mathrm{~kg} / \mathrm{m}^{2}$ and $<40 \mathrm{~kg} / \mathrm{m}^{2}$, and in $23.6 \%$ with a $\mathrm{BMI}>40 \mathrm{~kg} / \mathrm{m}^{2}$ (4). Despite this, OHS still remains under-recognized. In one study of obese patients (BMI $>35 \mathrm{~kg} / \mathrm{m}^{2}$ ) admitted to the hospital, $23 \%$ of OHS patients were correctly diagnosed and only $13 \%$ received treatment for OHS on discharge (5).

Because the rates of obesity are rising rapidly, the prevalence of $\mathrm{OHS}$ is likely to increase. It is estimated that the prevalence of morbid obesity $\left(\mathrm{BMI}>40 \mathrm{~kg} / \mathrm{m}^{2}\right)$ in the United States has quadrupled between 1986 and 2000 (6). Similar trends are evident in Canada: between 1979 and 2004, the obesity rate in Canadian adults has increased from $13.8 \%$ to $23.1 \%$ while the percentage of Canadian adults with class III obesity has tripled $(0.9 \%$ to $2.7 \%)(7)$. It is, therefore, not surprising that OHS is one of the most common reasons to initiate NIV. In a recent study of 1526 adults who started HMV in Sweden between 1996 and 2005 (8), OHS constituted the largest group ( $n=422$ [28\%]). In another study (9), 59 of 111 patients who received nocturnal HMV in New Zealand had OHS. A review of all HMV prescriptions in a Swedish registry between 1996 and 2002 (10) revealed that the OHS group had the highest increase ( $8 \%$ to $17 \%$ ) of all ventilated patients.

The majority of OHS subjects present with symptoms of OSA, but may also experience headaches, dyspnea and limb edema. OHS subjects have been shown to have increased mortality, hospitalization rates, high prevalence of pulmonary hypertension and increased use of health care resources. Decreased HRQoL, vigilance and $\mathrm{CO}_{2}$ sensitivity have also been demonstrated. When compared with a BMImatched population, OHS patients exhibit high rates of congestive heart failure, angina and pulmonary hypertension (11). Compared with eucapnic patients with OSA, patients with OHS have a lower QoL, experience more somnolence, incur higher health care expenses and greater risk of pulmonary hypertension (12). OHS patients have higher rates of intensive care unit admissions and a greater need for invasive mechanical ventilation (4).

\section{Key evidence}

The literature search identified 11 studies $(11,13-22)$ of HMV involving $378 \mathrm{OHS}$ patients treated with bilevel or volume-cycled ventilation $(n=274)$ or continuous PAP (CPAP) $(n=104)$. The majority of studies were prospective cohort or retrospective in design, had different enrollment criteria, used different modes of ventilation and had different places of initiation of therapy, variable follow-up and dropout rates. It must be emphasized that CPAP is not a ventilatory device and is not routinely used to treat hypoventilation; however, it is included in the present review because there are studies demonstrating its efficacy in a subset of OHS patients.

\section{Conclusion}

The existing evidence indicates that HMV using NIV is effective in the majority of OHS patients and results in significant improvement in symptoms of somnolence, dyspnea, edema and sleep quality, as well as improvements in gas exchange, sleep architecture and HRQoL. While there is still uncertainty about the optimal ventilatory mode in OHS, and because only one RCT compared CPAP and bilevel PAP, the existing evidence shows that bilevel therapy is effective in the majority of OHS cases, while CPAP is effective in a subgroup of OHS subjects with mild OHS and OSA. Newer ventilatory support modalities with tidal volume assurance have shown promise; however, additional longterm studies are required.

\section{SECTION VII. RECOMMENDATIONS}

1. NIV is the treatment of choice for OHS. (Grade of recommendation $1 \mathrm{~A}$ )

2. In patients with OHS who have a minor degree of nocturnal desaturation and no nocturnal rise in $\mathrm{PaCO}_{2}, \mathrm{CPAP}$ is a reasonable initial therapy provided that follow-up is arranged within one to three months to evaluate response to therapy. (Grade of recommendation 1B)
3. Under circumstances when access to more than one device (bilevel PAP or CPAP) is limited, bilevel therapy is recommended. (Grade of recommendation $1 \mathrm{C}$ )

4. In patients with OHS who experience significant nocturnal desaturation or a nocturnal increase in $\mathrm{PaCO}_{2}$, bilevel PAP remains the therapy of choice. (Grade of recommendation $1 \mathrm{~B}$ )

5. Polysomnography is useful for titrating and confirming efficacy of bilevel pressures. (Grade of recommendation 1C)

\section{REFERENCES}

1. Crummy F, Piper A, Naughton M. Obesity and lung 2: Obesity and sleep disordered breathing. Thorax 2008;63:738-46.

2. Mokhlesi B, Kryger MH, Grunstein RR. Assessment and management of patients with obesity hypoventilation syndrome.

Proc Am Thorac Soc 2008;5:2:18-225.

3. Mokhlesi B, Tulaimat A, Faibussowitsch I, Wang Y, Evans AR. Obesity hypoventilation syndrome: Prevalence and predictors in patients with obstructive sleep apnea. Sleep Breath 2007;11:117-24.

4. Laaban JP, Chailleux E. Daytime hypercapnia in adult patients with obstructive sleep apnea syndrome in France before initiating nocturnal nasal continuous positive airway pressure therapy. Chest 2005;127:710-5.

5. Nowbar S, Burkart KM, Gonzales R, et al. Obesity-associated hypoventilation in hospitalized patients: Prevalence, effects, and outcome. Am J Med 2004;116:1-7.

6. Freedman DS, Khan LK, Serdula MK, Galuska DA, Dietz WH. Trends and correlates of class 3 obesity in the United States from 1990 through 2000. JAMA 2002;288:9:1758-61.

7. Tjepkema M. Nutrition: Findings from the 2004 Canadian Community Health Survey - adult obesity in Canada: Measured height and weight. Statistics Canada (Catalogue number 82-620MWE2005001).

8. Laub M, Midgren B. Survival of patients on home mechanical ventilation: A nationwide prospective study. Respir Med 2007;101:1074-8.

9. Hancox RJ, Whyte KF, Baxter JM. Home ventilation: The Green Lane Hospital experience. NZ Med J 2000;500-3.

10. Laub M, Berg S, Midgren B. Home mechanical ventilation in Sweden - inequalities within a homogenous health care system. Respir Med 2004;98:38-42.

11. Berg G, Delaive K, Manfreda J, Walld R, Kryger MH. The use of health care resources in obesity-hypoventilation syndrome. Chest 2001;120:377-83.

12. Mokhlesi B. Positive airway pressure titration in obesity hypoventilation syndrome: Continuous positive airway pressure or bilevel positive airway pressure. Chest 2007;131:1624-6.

13. Perez de Llano LA, Golpe R, Ortiz Piquer M, et al. Short-term and long-term effects of nasal intermittent positive pressure ventilation in patients with obesity-hypoventilation syndrome. Chest 2005;128:587-94.

14. Budweiser S, Riedl SG, Jorres RA, Heinemann F, Pfeifer M. Mortality and prognostic factors in patients with obesityhypoventilation syndrome undergoing non-invasive ventilation. J Intern Med 2007;262:375-83.

15. Heinemann F, Budweiser S, Dobroschke J, Pfeifer M. Non-invasive positive pressure ventilation improves lung volumes in the obesity hypoventilation syndrome. Respir Med 2007;101:1229-35.

16. Piper AJ, Wang D, Yee BJ, Barnes DJ, Grunstein RR. Randomised trial of CPAP vs. bi-level support in the treatment of obesity hypoventilation syndrome without severe nocturnal desaturation. Thorax 2008;63:395-401.

17. Hida W, Okabe S, Tatsumi K, et al. Nasal continuous positive airway pressure improves quality of life in obesity hypoventilation syndrome. Sleep Breath 2003;7:3-12.

18. Storre JH, Seuthe B, Fiechter R, et al. Average volume-assured pressure support in obesity hypoventilation. Chest 2006;130:815-21.

19. Banerjee D, Yee BJ, Piper AJ, Zwillich CW, Grunstein RR. Obesity hypoventilation syndrome: Hypoxemia during continuous positive airway pressure. Chest 2007;131:1678-84.

20. Kawata N, Tatsumi K, Jiro Terada J, et al. Daytime hypercapnia in obstructive sleep apnea syndrome. Chest 2007;132:1832-8. 
21. Chouri-Pontarollo N, Borel JC, Tamisier R, Wuyam B, Levy P, Pepin JL. Impaired objective daytime vigilance in obesityhypoventilation syndrome - impact of non-invasive ventilation. Chest 2007;131:148-55.

22. Masa JF, Celli, BR, Riesco JA, Hernandez M, Sanchez de Cos J, Disdier C. The obesity hypoventilation syndrome. Can it be treated with non-invasive mechanical ventilation. Chest 2001;119:1102-7.

\section{SECTION VIII. HMV IN PERSONS WITH SCIs}

\section{Introduction}

Respiratory complications continue to be one of the leading causes of morbidity and mortality in individuals with SCI, despite advances in SCI care, for which acute and long-term mortality rates have declined (1). Although research has suggested dramatic improvement in survival for individuals with SCI over the past few decades, this is only in the critical first few years postinjury (2), and the life expectancies of ventilator-dependent patients with SCI have not improved (1). The degree of respiratory impairment in individuals with SCI depends on the level and grade of injury. Complete high cervical cord lesions are associated with the greatest respiratory muscle dysfunction. With injuries affecting innervation of the abdominal muscles, the ability to cough and clear secretions is compromised, and strategies for management of airway secretions and prevention/treatment of atelectasis and pneumonia must be implemented.

Most patients acutely supported by a ventilator will recover spontaneous breathing (3); however, approximately $5 \%$ of individuals require ongoing ventilatory support (4). Respiratory function remains impaired in individuals with tetraplegia, and assisted ventilation may be indicated in patients with chronic injuries.

\section{Key evidence}

There are no RCTs involving mechanical ventilation in patients with SCI. Evidence consists of retrospective reviews and small case series, supported by consensus of the HMV expert panel.

In a survival analysis study, Shavelle et al (5) identified that trends in improved survival otherwise observed in SCI were not seen among ventilator-dependent SCI patients surviving the first critical years, and that ventilator dependency remained an independent risk factor for mortality. Respiratory complications were the leading cause of mortality, accounting for $31 \%$ of deaths (5). DeVivo and Ivie (6) identified significantly reduced life expectancy for ventilator-dependent individuals following spinal cord injury, even when controlled for age, sex and race. In adults, ventilator dependency is the strongest negative predictor of survival during the first year after hospital discharge.

Three surveys of VAIs with high tetraplegia (total $n=75$ VAIs in three studies [7-9]) suggested that QoL and life satisfaction are high. Recently, authors have reported improved QoL indicators for individuals who have been successfully implanted with phrenic nerve or diaphragmatic pacing (currently a research tool not yet approved in Canada), enabling ventilator-free breathing after long-term ventilator dependency $(10,11)$. Pacing is associated with better power-chair management, increased hospital discharge, phonation and sense of smell.

For patients who require assisted ventilation, noninvasive approaches are associated with fewer complications than invasive ventilation, as described in three retrospective studies. Noninvasive approaches require reasonably intact bulbar musculature and alert mental status. Bach and Alba (14) described a monitored sequence of manual and mechanical coughing techniques, progressive tracheostomy cuff deflation and adjustment of ventilator volumes in successfully converting 23 of 25 high tetraplegia patients from invasive to noninvasive support.

Retrospective reviews by Peterson et al (15) describe ventilator weaning protocols that compared intermittent mandatory ventilation with a progressive ventilator-free breathing (PVFB) approach, in which PVFB demonstrated a higher success rate. PVFB should be considered for appropriate patients with tetraplegia who are dependent on ventilation. There is greater support, albeit few studies, for PVFB than synchronized intermittent mandatory ventilation (15).
Alteration of pulmonary function and respiratory complications are a major cause of both morbidity and mortality in patients with SCI. There are no studies to provide direction for the long-term management of respiratory dysfunction in persons with SCI. Patients at risk for impaired airway clearance (ie, PCFs $<270 \mathrm{~L} / \mathrm{min}$ ) are encouraged to use LVR and preventive airway clearance strategies. Individuals with SCIs remain at risk for the development of sleep disordered breathing and those with higher injuries for respiratory failure. As such, regular follow-up every six to 12 months is recommended with a review of respiratory function, nocturnal gas exchange and any symptoms that would indicate respiratory compromise. Consideration should be given to initiation of NIV in such individuals. In stable patients identified with uncomplicated OSA, CPAP therapy alone may be all that is required with regular follow-up to exclude the development of respiratory failure, which would require PPV.

\section{Conclusion}

Ventilator dependency remains a negative predictor for survival following $\mathrm{SCI}$, and invasive ventilation is associated with increased complications. Attempts to wean from ventilation should be considered whenever possible. Limited evidence suggests progressive ventilator-free breathing is more successful than intermittent mandatory ventilation. When ventilation is required, NIV has been demonstrated to be associated with fewer complications. Patients requiring home ventilation report good $\mathrm{QoL}$ and well-being, with recent case series $(10,11)$ finding improved QoL with diaphragmatic and phrenic nerve pacing options over ventilator dependence. Although there are no trials in SCI to inform on long-term management, expert consensus supports lifelong management of airway clearance and monitoring of potential needs for ventilatory support.

\section{SECTION VIII. RECOMMENDATIONS}

1. Protocols for weaning with PVFB should be considered for appropriate patients with tetraplegia who are dependent on ventilation. (Grade of recommendation $1 \mathrm{C}$ )

2. Each patient must be individually evaluated for the need for long-term ventilation either acutely or in follow-up. Noninvasive support is preferable to invasive ventilation. (Grade of recommendation 1C)

3. Phrenic nerve pacing is recommended in selected individuals as an alternative to PPV alone. (Grade of recommendation 2C)

4. Regular airway clearance techniques (LVR, MAC and MI-E), clinical assessment and ongoing monitoring of pulmonary function is recommended to ensure adequate airway clearance. (Grade of recommendation 1C)

5. In the long term, individuals with SCI require regular monitoring to identify the development of sleep disordered breathing or respiratory failure and evaluate the need for NIV. (Consensus)

\section{REFERENCES}

1. DeVivo MJ, Krause JS, Lammertse DP. Recent trends in mortality and causes of death among persons with spinal cord injury. Arch Phys Med Rehabil 1999;80:1411-9.

2. Strauss DJ, DeVivo MJ, Paculdo DR, Shavelle RM. Trends in life expectancy after spinal cord injury. Arch Phys Med Rehabil 2006;87:1079-85.

3. Sassoon CSH, Baydur A. In: VW Lin, ed. Respiratory dysfunction in spinal cord disorders. Spinal Cord Medicine Principles and Practice. New York: Demos Medical Publishing Inc, 2003;155-68.

4. Zimmer MB, Nantwi K, Goshgarian HG. Effect of spinal cord injury on the respiratory system: Basic research and current clinical treatment options. J Spinal Cord Med 2007;30:319-30.

5. Shavelle RM, DeVivo MJ, Strauss DJ, Paculdo DR, Lammertse DP, Day SM. Long-term survival of persons ventilator dependent after spinal cord injury. J Spinal Cord Med 2006;29:511-9.

6. DeVivo MJ, Ivie CS. Life expectancy of ventilator-dependent persons with spinal cord injuries. Chest 1995;108:226-32. 
7. Nelson VS, Dixon PJ, Warschausky SA. Long-term outcome of children with high tetraplegia and ventilator dependence. J Spinal Cord Med 2004;27:S93-7.

8. Hall KM, Knudsen ST, Wright J, Charlifue SW, Graves DE, Werner P. Follow-up study of individuals with high tetraplegia (C1-C4) 14 to 24 years post-injury. Arch Phys Med Rehabil 1999;80:1507-13.

9. Bach JR, Tilton MC. Life satisfaction and well-being measures in ventilation assisted individuals with traumatic tetraplegia. Arch Phys Med Rehabil 1994;75:626-32.

10. Hirschfeld S, Exner G, Luukkaala T, Baer GA. Mechanical ventilation or phrenic nerve stimulation for treatment of spinal cord injury-induced respiratory insufficiency. Spinal Cord 2008;46:738-42.

11. Onders RP, Elmo MJ, Ignagni AR. Diaphragm pacing stimulation system for tetraplegia in individuals injured during childhood or adolescence. J Spinal Cord Med 2007;30:S25-9.

12. Bach JR, Alba AS, Saporito LR. Intermittent positive pressure ventilation via the mouth as an alternative to tracheostomy for 257 ventilator users. Chest 1993;103:174-82.

13. Bach JR. Alternative methods of ventilator support for the patient with ventilatory failure due to spinal cord injury. J Am Paraplegia Soc 1991;14:158-74.

14. Bach JR, Alba AS. Non-invasive options for ventilator support of the traumatic high level ventilator patient. Chest 1990;98:613-9.

15. Peterson P, Brooks CA, Mellick D, Whiteneck G. Protocol for ventilator management in high tetraplegia. Top Spinal Cord Inj Rehabil 1997;2:101-6.

\section{SECTION IX. HMV FOR PATIENTS WITH DMD}

\section{Introduction}

DMD occurs in approximately one in 3500 live male births. The disease is caused by mutations in the dystrophin gene, and leads to widespread muscle fibre necrosis along with fibrosis and fatty cell infiltration of muscle including the respiratory muscles. Becker MD is a less prevalent and more slowly progressive form of the disease, in which aberrant but partially functional forms of dystrophin are expressed in muscle. In DMD patients, nocturnal or full-time home ventilation has been used for 25 to 30 years, but has only come into frequent use since the 1990s.

\section{Key evidence}

In the majority of the studies selected for inclusion and analysis, the subject population consisted solely of DMD patients, although some studies containing a mixed population of NMDs were also included when there was a subgroup analysis of DMD patients, or when the data were deemed to be especially relevant and investigations specific to the DMD population were lacking. The studies addressed one or more clinical outcomes including survival, gas exchange (including during sleep) and pulmonary function, QoL and hospitalizations, and mode as well as timing of initiation for home ventilation.

Although the early experience with mechanical ventilation in DMD patients mostly involved the use of negative pressure devices, these have been largely abandoned in routine clinical practice due to problems of upper airway obstruction during sleep (1) as well as cumbersome application. Therefore, the studies included in this analysis are mostly limited to those examining the effects of PPV.

\section{Conclusion}

Despite limitations including small numbers of controlled studies specific to the influence of long-term mechanical ventilation on survival in DMD patients, as well as studies including patients with a heterogeneous group of NMDs or chest wall diseases, strong inferences regarding the benefits of long-term mechanical ventilation in DMD patients have been drawn from the literature. Among these are the significant improvements in survival that have coincided with the period during which NIPPV has come into more frequent use (2-6). Especially notable is that the survival benefit may partially be related to other improvements in the care of DMD patients, perhaps due in part, to improved management of the associated cardiomyopathy.

Pulmonary function should be monitored at least yearly, and patients carefully questioned about symptoms suggestive of nocturnal hypoventilation. The frequency should increase with progression of the disease because once VC falls to $<40 \%$ predicted, patients are at significant risk for the development of nocturnal hypercapnia (7-9), followed within one to two years by clinical deterioration (10). Although full polysomnography with $\mathrm{CO}_{2}$ monitoring is generally preferred to distinguish upper airway obstructive events from hypoventilation, and to confirm the occurrence of rapid eye movement sleep, we recognize that this may not be readily available and can also represent a significant burden for some patients. Depending on the specific circumstances and logistical constraints, alternative forms of respiratory monitoring during sleep (ideally including both oximetry and $\mathrm{CO}_{2}$ measurements) can also be used.

The available evidence strongly suggests that once diurnal hypercapnia has developed, QoL is reduced $(10,11)$ and the risk of mortality within one year is high without ventilatory support (12). Under these conditions, nocturnal NIV can be effective in helping to improve daytime symptoms and reduce the degree of diurnal hypercapnia during spontaneous breathing $(9,12-14)$. In addition, failure to correct isolated nocturnal hypoventilation (equivalent to $\mathrm{tCO}_{2}>50 \mathrm{mmHg}$ ), even in asymptomatic patients, was shown to be a harbinger of clinical deterioration within a relatively short time period in one randomized study of patients with a mixed group of NMDs (10). At minimum, very close follow-up is needed in asymptomatic DMD patients with isolated nocturnal hypercapnia because it appears that many such patients could become symptomatic and require NIV within the next one to two years. In addition, we believe that nocturnal NIV should be offered to DMD patients if major hypoxemia during sleep has been documented, even when patients are asymptomatic.

If NIV must be extended beyond the night to include a substantial period of daytime ventilatory support for relief of symptoms and maintenance of acceptable blood gases, strong consideration should be given to the avoidance of invasive tracheostomy in favour of mouthpiece ventilation; depending on local logistical considerations, patient preference, and other factors such as bulbar and cognitive function, should be considered because these may preclude the use of mouthpiece ventilation.

Airway clearance strategies are critical to the success of NIV in patients with DMD and should be directed at achieving PCFs $\geq 270 \mathrm{~L} / \mathrm{min}$ using LVR and MAC techniques as required. MI-E should be considered for those unable to obtain a PCF of $270 \mathrm{~L} / \mathrm{min}$ (15).

\section{SECTION IX. RECOMMENDATIONS}

\section{For monitoring}

1. Carefully question and educate patients to report symptoms consistent with hypoventilation, including disturbed sleep, excessive daytime sleepiness, morning headache and weight loss. (Grade of recommendation 1C)

2. Measure VC, MIP, maximal expiratory pressure, PCF and awake oxyhemoglobin saturation by pulse oximetry at least yearly; if $\mathrm{VC}<40 \%$ predicted, also monitor awake $\mathrm{CO}_{2}$ tension by noninvasive methods or ABG analysis. (Grade of recommendation 1C)

3. Perform an evaluation of ventilation during sleep if there are symptoms consistent with nocturnal hypoventilation or other forms of sleep disordered breathing (Grade of recommendation $1 \mathrm{C}$ ).

4. In the absence of such symptoms, periodic screening for sleep disordered breathing should also be considered once $\mathrm{FEV}_{1}$ or FVC is $<40 \%$ predicted. (Grade of recommendation 1C)

For treatment

1. Offer nocturnal NIV to patients with diurnal hypercapnia (daytime arterial $\mathrm{PCO}_{2}>45 \mathrm{mmHg}$ ), or when there is documented nocturnal hypercapnia and the presence of symptoms consistent with hypoventilation. (Grade of recommendation $1 \mathrm{~B}$ ) 
2. Institution of NIV during sleep should be offered to patients demonstrating a major degree of nocturnal hypoxemia, even if asymptomatic. (Grade of recommendation 2C)

3. When bilevel ventilation is used, backup respiratory rates are recommended during sleep while on NIV to reduce the work of breathing associated with breath initiation. (Grade of recommendation $1 \mathrm{C}$ )

4. Individualize the decision about the transition from nocturnal NIV to daytime ventilation by carefully evaluating patient factors (symptoms, bulbar involvement, patient preference, etc) and available resources. In patients requiring daytime ventilation, strongly consider mouthpiece ventilation as an alternative to invasive tracheostomy. (Grade of recommendation $1 \mathrm{~B}$ )

5. Lung volume recruitment manoeuvres should be introduced with declining VC. (Section I. Airway Clearance). (Grade of recommendation $1 \mathrm{C}$ )

6. Methods to assist secretion clearance should be initiated when $\mathrm{PCF}<270 \mathrm{~L} / \mathrm{min}$. (Section 1. Airway Clearance). (Grade of recommendation $1 \mathrm{C})$

\section{REFERENCES}

1. Hill NS, Redline S, Carskadon MA, Curran FJ, Millman RP. Sleep disordered breathing in patients with Duchenne muscular dystrophy using negative pressure ventilators. Chest 1992;102:1656-62.

2. Eagle M, Baudouin SV, Chandler C, Giddings DR, Bullock R, Bushby K. Survival in Duchenne muscular dystrophy: Improvements in life expectancy since 1967 and the impact of home nocturnal ventilation. Neuromuscul Disord 2002;12:926-9.

3. Eagle M, Bourke J, Bullock R, et al. Managing Duchenne muscular dystrophy - the additive effect of spinal surgery and home nocturnal ventilation in improving survival. Neuromuscul Disord 2007;17:470-5.

4. Konagaya M, Sakai M, Wakayama T, Kimura S, Kuru S, Yasuma F. Effect of intermittent positive pressure ventilation on life-span and causes of death in Duchenne muscular dystrophy. Rinsho Shinkeigaku 2005;45:643-6.

5. Yasuma F, Konagaya M, Sakai M, Kuru S, Kawamura T. A new lease on life for patients with Duchenne muscular dystrophy in Japan. Am J Med 2004;117:363.

6. Curran FJ. Night ventilation by body respirators for patients in chronic respiratory failure due to late stage Duchenne muscular dystrophy. Arch Phys Med Rehabil 1981;62:270-4.

7. Toussaint M, Chatwin M, Soudon P. Mechanical ventilation in Duchenne patients with chronic respiratory insufficiency: Clinical implications of 20 years published experience. Chron Respir Dis 2007;4:167-77.

8. Toussaint M, Steens M, Soudon P. Lung function accurately predicts hypercapnia in patients with Duchenne muscular dystrophy. Chest 2007;131:368-75.

9. Hukins CA, Hillman DR. Daytime predictors of sleep hypoventilation in Duchenne muscular dystrophy. Am J Respir Crit Care Med 2000;161:166-70.

10. Gibson B. Long-term ventilation for patients with Duchenne muscular dystrophy: Physicians' beliefs and practices. Chest 2001;119:940-6.

11. Windisch W, Freidel K, Schucher B, et al. Evaluation of health related quality of life using the MOS 36-Item Short-Form Health Status Survey in patients receiving non-invasive positive pressure ventilation. Intensive Care Med 2003;29:615-21.

12. Jeppesen J, Green A, Steffensen BF, Rahbek J. The Duchenne muscular dystrophy population in Denmark, 1977-2001:

Prevalence, incidence and survival in relation to the introduction of ventilator use. Neuromuscul Disord 2003;13:804-12.

13. Leger P, Bedicam JM, Cornette A, et al. Nasal intermittent positive pressure ventilation. Long-term follow-up in patients with severe chronic respiratory insufficiency. Chest 1994;105:100-5.

14. Kinali M, Manzur AY, Mercuri E, et al. UK physicians' attitudes and practices in long-term non-invasive ventilation of Duchenne muscular dystrophy. Pediatr Rehabil 2006;9:351-64.

15. Finder JD, Birnkrant D, Carl J, et al; American Thoracic Society. Respiratory care of the patient with Duchenne muscular dystrophy; ATS Consensus Statement. Am J Respir Crit Care Med 2004;170:456-65.

\section{SECTION X. HMV FOR PATIENTS WITH OTHER MDs AND MYOPATHIES}

\section{Introduction}

Myopathies and MDs represent a large group of diseases with different modes of inheritance and different clinical features. Many myopathies and MDs are eventually complicated by respiratory failure and death $(1,2)$. Causes of respiratory failure may include general respiratory muscle weakness occurring together with limb weakness as in limb girdle dystrophy. There may be selective diaphragm involvement as in facioscapulohumeral dystrophy or acid maltase deficiency. These conditions, with predominant diaphragm weakness, would be best assessed by measurement of supine as well as sitting VC. There may be associated skeletal dysmorphism-like pectusexcavatum and kyphoscoliosis as in Emery-Dreifuss muscular dystrophy. There may be impairments of central drive contributing to alveolar hypoventilation as in myotonic dystrophy. There may be coexisting interstitial pulmonary involvement leading to fibrosis in the inflammatory myopathies such as polymyositis and dermatomyositis. Eventually, consideration must be given to long-term ventilatory support for patients suffering from these diseases who develop respiratory failure.

\section{Key evidence}

There are few studies (3-6) analyzing long-term ventilatory support for respiratory failure in specific myopathies and MDs other than DMD. MDs and myopathies are often mixed with other NMDs and chest wall disorders in most studies (7-10). Moreover, patients with these diseases often represent only a small fraction of cases included.

The general indication for long-term ventilatory support is the presence of daytime hypercapnia. Application of nocturnal NIV when these individuals become hypercapnic during the day prolongs survival, improves nocturnal and diurnal ABG tensions, normalizes sleep patterns and enhances HRQoL.

One RCT concluded that nocturnal hypoventilation without daytime hypercapnia is also a valid indication for HMV in patients with NMDs and chest wall disorders (8). These patients are likely to deteriorate with the development of daytime hypercapnia and/or progressive symptoms within two years as was seen in the control group. In this study, 11 of 48 patients had MDs or myopathies.

Another study (5) reported relationships between nocturnal respiratory variables and daytime lung function to identify potential patients with such nocturnal hypoventilation without reliance on expensive and frequently unavailable tests such as polysomnography. Of the 42 patients with NMD, 30 of 42 had MDs and myopathies. The authors concluded that bedside spirometry testing at six- to 12 -month intervals provided a low cost, reproducible way to determine which patients were at risk. Patients with $\mathrm{VC}>60 \%$ are unlikely to have any nocturnal hypoventilation, indicating good respiratory reserve and minimal risk of respiratory complications. Those with $\mathrm{VC}<60 \%$ were more likely to have nocturnal hypoventilation, indicating reduced respiratory reserve and the potential need for polysomnography or alternative nocturnal monitoring. Those with $\mathrm{VC}<40 \%$ commonly demonstrated diurnal hypercapnia.

\section{Conclusion}

Based on recommendations made for other groups of NMD, the opinion of the expert panel and a small number of studies investigating home ventilation that included patients with MDs and myopathies, long-term ventilatory support for these patients is recommended when there is daytime hypercapnia or symptoms and signs of nocturnal hypoventilation. Periodic spirometry testing will help to identify patients as being of lesser or greater risk of respiratory failure. As for other chronic NMDs, the frequency of follow-up should be at least every six to 12 months, but is also determined by the rapidity of disease progression. 


\section{SECTION X. RECOMMENDATIONS}

1. Obtain periodic clinical assessment and spirometry at six- to 12-month intervals, including sitting (plus supine if diaphragmatic weakness is suspected) spirometric testing. (Grade of recommendation 1C)

2. Consider monitoring for sleep disordered breathing in patients with $\mathrm{VC}<60 \%$. (Grade of recommendation $1 \mathrm{C}$ )

3. Consider $\mathrm{ABG}$ or nocturnal measure of $\mathrm{CO}_{2}$ in patients with $\mathrm{VC}<40 \%$ to exclude hypercapnia. (Grade of recommendation $1 \mathrm{C}$ )

4. NIV should be offered when there is daytime hypercapnia or symptomatic nocturnal hypoventilation. (Grade of recommendation $1 \mathrm{C}$ )

5. Assess airway clearance ability with PCFs and implement cough-assistance strategies (Section I. Airway Clearance). (Grade of recommendation 1C)

\section{REFERENCES}

1. Howard RS, Wiles CM, Hirsch NP, et al. Respiratory involvement in primary muscle disorders: Assessment and management. Q J Med 1993;86:175-89.

2. Howard RS, Davidson C. Long term ventilation in neurogenic respiratory failure. J Neurol Neurosurg Psych 2003;74:iii24.

3. Mellies U, Ragette R, Schwake C, et al. Long-term non-invasive ventilation in children and adolescents with neuromuscular disorders. Eur Respir J 2003;22:631-6.

4. Nugent AM, Smith IE, Shneerson JM. Domiciliary-assisted ventilation in patients with myotonic dystrophy. Chest 2002;121:459-64.

5. Ragette R, Mellies U, Schwake C, et al. Patterns and predictors of sleep disordered breathing in primary myopathies. Thorax 2002;57:724-8.

6. Leger P, Bedicam JM, Cornette A, et al. Nasal intermittent positive pressure ventilation. Long-term follow-up in patients with severe chronic respiratory insufficiency. Chest 1994:105:100-5.

7. Annane D, Orlikowski D, Chevert S, Chevrolet JC, Raphael JC. Nocturnal mechanical ventilation for chronic hypoventilation in patients with neuromuscular and chest wall disorders. Cochrane Database Syst Rev 2007;(4):CD001941.

8. Ward S, Chatwin M, Heather S, Simonds AK. Randomised controlled trial of non-invasive ventilation (NIV) for nocturnal hypoventilation in neuromuscular and chest wall disease patients with daytime normocapnia. Thorax 2005;60:1019-24.

9. Janssens JP, Cicotti E, Fitting JW, Rochat T. Non-invasive home ventilation in patients over 75 years of age: Tolerance, compliance, and impact on quality of life. Respir Med 1998;92:1311-20.

10. Simonds AK. Recent advances in respiratory care for neuromuscular disease. Chest 2006;130:1879-86.

\section{SECTION XI. HMV FOR PATIENTS WITH MYOTONIC DYSTROPHY (SMD)}

\section{Introduction}

Myopathies and MDs represent a large group of diseases. Dystrophia myotonica (DM) (also known as myotonic dystrophy or Steinert's disease) is of special interest because of its relatively high incidence in Canada and even more so in Quebec. It is the most frequent adult onset MD, with a worldwide prevalence of 14 per 100,000 population and more than 10 times higher in the Saguenay-Lac-Saint-Jean region of Quebec (1). It is an autosomal dominant disorder resulting from an unstable myotonin kinase gene at $19 \mathrm{q} 13.3$.

Hypoventilation in DM may be related to respiratory muscle weakness, upper-airway obstruction, reduced chest wall compliance or be related, in some patients, to a reduced $\mathrm{CO}_{2}$ responsiveness (2). Hypercapnia in DM may be present even with relative preservation of VC and maximal breathing capacity. Other features of DM include myotonia, cardiac conduction defects (3), variable cognitive impairment and personality disorders $(4,5)$ that create challenges in establishing relationships in social life and in providing respiratory care. Respiratory failure is a major cause of death among DM patients. Aspiration pneumonia and perioperative pulmonary complications are common (1).

\section{Key evidence}

Very few articles address long-term ventilatory support for patients with chronic respiratory failure related to DM. Only a few studies investigating nonspecific NMDs included some DM patients. Only one relevant case series dedicated to long-term ventilation for DM patients was found (6). This study was a descriptive analysis of $16 \mathrm{DM}$ patients referred for assisted ventilation. The authors describe a good physiological response to assisted ventilation but a lower compliance with therapy than patients with other NMDs. There are insufficient data to comment about the impact of long-term ventilatory support on HRQoL for patients with DM. Other recommendations must be extrapolated from key evidence for HMV in other groups of NMDs (Section X).

\section{Conclusion}

Recommendations are based on one specific study of home ventilated DM patients (6); a few studies about respiratory pathophysiology $(2,7,8)$; other features $(1,3,4,5,9,10)$ of DM; recommendations made for HMV in other groups of NMDs (11-15); and the consensus of the HMV committee.

Long-term ventilatory support for patients with myotonic dystrophy must be considered when there is daytime hypercapnia or symptoms and signs of nocturnal hypoventilation. Because of some biopsychosocial issues, adherence to long-term ventilatory support may be lower in DM patients, and they may require extra support from caregivers and health care professionals. Selection of an appropriate ventilator and interface for each patient is an important aspect of management in this group of patients. Because of facial muscle weakness, a considerable number of patients may have oral air leak when using nasal masks so they often require a full oronasal mask.

Beyond the scope of these HMV recommendations, caregivers must consider other important issues of DM patient management: the need for periodic assessment of cardiac conduction, indications for cardiac pacemaker implantation (16), occasional usefulness of psychostimulant drugs such as modafinil for idiopathic daytime sleepiness (17), and awareness of increased risk of anesthetic and surgical complications (18).

\section{SECTION XI. RECOMMENDATIONS}

1. Obtain six to 12 monthly clinical assessment of symptoms of daytime or nocturnal hypoventilation. (Grade of recommendation $1 \mathrm{C}$ )

2. Obtain yearly $\mathrm{VC}$ and consider daytime $\mathrm{PaCO}_{2}$ measurement, even with mild reductions of $\mathrm{VC}$ when patients exhibit symptoms of hypoventilation. (Grade of recommendation 1C)

3. Consider overnight oximetry or polysomnography when there are symptoms of nocturnal hypoventilation. (Grade of recommendation $1 \mathrm{C}$ )

4. Long-term NIV should be offered to patients with daytime hypercapnia or symptomatic nocturnal hypoventilation as for other NMDs. (Grade of recommendation 1C)

5. Carefully assess motivation and ability to adhere to treatment with patients and their caregivers before initiating long-term ventilatory support. (Consensus)

6. Reassess every six months to verify treatment adherence and provide extra help and motivation as needed. (Consensus)

7. Assess airway clearance ability with PCFs and implement cough-assistance strategies (Section I. Airway Clearance). (Grade of recommendation 1C)

\section{REFERENCES}

1. Mathieu J, Allard P, Potvin L, Prévost C, Bégin P. A 10-year study of mortality in a cohort of patients with myotonic dystrophy. Neurology 1999;12;52:1658-62. 
2. Bégin P, Mathieu J, Almirall J, Grassino A. Relationship between chronic hypercapnia and inspiratory-muscle weakness in myotonic dystrophy. Am J Respir Crit Care Med 1997;156:133-9.

3. Groh WJ, Groh MR, Saha C, et al. Electrocardiographic abnormalities and sudden death in myotonic dystrophy type 1 . N Eng J Med 2008;19:358:2688-97.

4. Franzese A, Antonini G, Iannelli M, et al. Intellectual function and personality in a subject with non-congenital myotonic muscular dystrophy. Psychol Rep 1991;68:723-32.

5. Palmer BW, Boone KB, Chang L, Lee A, Black S. Cognitive deficits and personality patterns in maternally versus paternally inherited myotonic dystrophy. J Clin Exp Neuropsychol 1994;16:784-95.

6. Nugent A-M, Smith IE, Shneerson JM. Domiciliary-assisted ventilation in patients with myotonic dystrophy. Chest 2002;121:459-64.

7. Veale D, Cooper BG, Gilmartin JJ, Walls TJ, Griffith CJ, Gibson GJ. Breathing pattern awake and asleep in patients with myotonic dystrophy. Eur Respir J 1995;8:815-8.

8. Cirignotta F, Mondini S, Zucconi M, et al. Sleep-related breathing impairment in myotonic dystrophy. J Neurol 1987;235:80-5.

9. Martínez-Rodríguez JE, Lin L, Iranzo A, et al. Decreased hypocretin-1 (Orexin-A) levels in the cerebrospinal fluid of patients with myotonic dystrophy and excessive daytime sleepiness. Sleep 2003;26:287-90.

10. Ciafaloni E, Mignot E, Sansone V, et al. The hypocretin neurotransmission system in myotonic dystrophy type 1 . Neurology 2008;70:226-30.

11. Howard RS, Wiles CM, Hirsch NP, et al. Respiratory involvement in primary muscle disorders: Assessment and management. Q J Med 1993;86:175-89.

12. Howard RS, Davidson C. Long-term ventilation in neurogenic respiratory failure. J Neurol Neurosurg Psych 2003;74:iii24.

13. Ward S, Chatwin M, Heather S, Simonds AK. Randomised controlled trial of non-invasive ventilation (NIV) for nocturnal hypoventilation in neuromuscular and chest wall disease patients with daytime normocapnia. Thorax 2005;60:1019-24.

14. Ragette R, Mellies U, Schwake C, Voit T, Teschler H. Patterns and predictors of sleep disordered breathing in primary myopathies. Thorax 2002;57:724-8.

15. Mellies U, Ragette R, Schwake C, et al. Long-term non-invasive ventilation in children and adolescents with neuromuscular disorders. Eur Respir J 2003;22:631.

16. Gregoratos G, Abrams J, Epstein AE, et al. ACC/AHA/NASPE 2002 Guideline update for implantation of cardiac pacemakers and anti-arrhythmia devices: Summary article. A report of the American College of Cardiology/American Heart Association Task Force on practice guidelines (ACC/AHA/NASPE committee to update the 1998 pacemaker guidelines). Circulation 2002;106:2145.

17. Annane D, Moore DH, Barnes PR, Miller RG. Psychostimulants for hypersomnia (excessive daytime sleepiness) in myotonic dystrophy. Cochrane Database Syst Rev 2006;3:CD003218.

18. Mathieu J, Allard P, Gobeil G, et al. Anesthetic and surgical complications in 219 cases of myotonic dystrophy. Neurology 1997;49:1646.

\section{SECTION XII. HMV FOR PATIENTS WITH POST-POLIO SYNDROME}

\section{Introduction}

Late-onset of respiratory problems in post-polio syndrome (PPS) often occurs in individuals who initially exhibit respiratory muscle involvement $(1,2)$. Several series have shown an increased risk of respiratory failure with $\mathrm{VCs}<50 \%$ predicted (2-4). Scoliosis, respiratory infection, obesity and concurrent lung disease may play a role in the respiratory deterioration; however, the onset of nocturnal hypoventilation is often insidious $(1,3,5,6)$.

\section{Key evidence}

There are no RCTs on the initiation of HMV in PPS. Recommendations informing this section are based on descriptive retrospective and prospective series of mixed populations of patients including those with PPS and consensus of the expert HMV committee.

\section{Conclusion}

There is little evidence to suggest that patients with PPS who develop respiratory insufficiency should be treated differently from other patients with slowly progressive NMD. When VC falls below $50 \%$, evaluation for possible hypoventilation should be considered (or sooner if symptoms are present); however, this is based on low-quality evidence. A Cochrane Systematic Review of nocturnal mechanical ventilation for chronic hypoventilation secondary to NMDs and chest wall disorders only included a few PPS patients in the mixed population of patients (7). Although the evidence of therapeutic benefit was weak, it supported the suggestion that the symptoms of chronic hypoventilation were alleviated. Prospective and retrospective series report reversal of symptoms and signs of hypoventilation, and fairly good five-year survival data after institution of noninvasive HMV (8-14).

\section{SECTION XII. RECOMMENDATIONS}

1. Yearly assessment of $\mathrm{VC}$ is recommended from the time of presentation of PPS. (Grade of recommendation 1C)

2. If $\mathrm{VC}>50 \%$ with symptoms of hypoventilation, perform measurements of daytime ABGs, overnight oximetry and consider polysomnography. (Grade of recommendation 1C)

3. When $\mathrm{VC}<50 \%$, perform $\mathrm{ABG}$ analysis and/or nocturnal oximetry yearly. (Grade of recommendation $2 \mathrm{C}$ )

4. With confirmation of the presence of chronic hypoventilation, offer NIV. (Grade of recommendation 1C)

5. Assess airway clearance ability with PCFs and implement cough assistance strategies (Section I. Airway Clearance). (Grade of recommendation 1C)

\section{REFERENCES}

1. Bach JR. Management of post-polio respiratory sequelae. Ann NY Acad Sci 1995;25:753:96-102.

2. Thorsteinsson G. Management of post-polio syndrome. Mayo Clin Proc 1997;72:627-38.

3. Migren B. Lung function and clinical outcome in post-polio patients: A prospective cohort study during 11 years. Eur Respir J 1997;10:146-9.

4. Pehrsson K, Nachemson A, Olofson J, Ström K, Larsson S. Respiratory failure in scoliosis and other thoracic deformities. A survey of patients with home oxygen or ventilator therapy in Sweden. Spine 1992;17:714-8.

5. Jubelt B. Post-polio syndrome. Current Treatment Options Neurol 2004;6:87-93.

6. Howard RS, Wiles CM, Spencer GT. The late sequelae of poliomyelitis. Q J Med 1988;66:219-32.

7. Annane D, Orlikowski D, Chevret S, et al. Nocturnal mechanical ventilation for chronic hypoventilation in patients with neuromuscular and chest wall disorders. Cochrane Database Syst Rev 2008; (4):CD001941.

8. Bach JR, Alba AS, Bohatiuk G, Saporito L, Lee M. Mouth intermittent positive pressure ventilation in the management of post-polio respiratory insufficiency. Chest 1987;91:859-64.

9. Bach JR, Alba AS, Shin D. Management alternatives for post-polio respiratory insufficiency. Assisted ventilation by nasal or oral-nasal interface. Am J Phys Med Rehabil 1989;68:264-71.

10. Curran FJ, Colbert AP. Ventilator management in Duchenne muscular dystrophy and post-poliomyelitis syndrome: Twelve years' experience. Arch Phys Med Rehabil 1989;70:180-5.

11. Duiverman ML, Bladder G, Meinesz AF, Wijkstra PJ. Home mechanical ventilatory support in patients with restrictive ventilatory disorders: A 48-year experience Respir Med 2006;100:56-65.

12. Janssens JP, Derivaz S, Breitenstein E, et al. Changing patterns in long-term non-invasive ventilation: A 7-year prospective study in the Geneva Lake area. Chest 2003;123:67-79.

13. Simonds AK, Elliott MW. Outcome of domiciliary nasal intermittent positive pressure ventilation in restrictive and obstructive disorders. Thorax 1995;50:604-9.

14. Laub M, Midgren B. Survival of patients on home mechanical ventilation: A nationwide prospective study. Respir Med 2007;101:1074-8. 


\section{SECTION XIII. ETHICAL ISSUES IN THE CARE OF HOME-VENTILATED PATIENTS}

\section{Introduction}

HMV is accompanied by several complex and unique ethical issues and perspectives. It challenges the traditional framework of care provided in a hospital setting, introducing a wide array of new challenges and experiences. Home ventilation necessarily promotes certain fundamental ethical principles, such as respect for autonomy and independence of patients, while raising new concerns such as isolation, vulnerability and safety. In a home setting, there exist many variables within each environment that need to be addressed on an individual and personal level (1). Furthermore, HMV may also play a key role in issues surrounding the allocation of scarce resources because it not only fosters greater independence for patients requiring this assistance, but also increases availability in the number of limited beds in intensive care units (2-5).

\section{Key evidence}

A survey of the current literature on the ethics of HMV revealed that there is little written in this field regarding specific ethical concerns raised in the home environment for these patients. Evidence surrounding the present trend to promote home health care and transitioning patients back to their home environments is explored and examined to demonstrate the importance and extraordinary benefit of a communitybased health care. Furthermore, there is much evidence to reveal that HMV is also a more cost-effective method to alleviate strains on scarce health care resources, along with providing enormous mental and emotional benefits for patients and family members (6-8). A variety of studies reveal a generally positive impression of HMV among patients due to the increased independence experienced by these individuals $(3,7)$. Another area that needs much more research and investigation is that of relative safety of patients receiving HMV due to the number of unknown factors associated with care in the community $(9,10)$.

\section{Conclusion}

In the context of HMV, patients, their families and clinicians face a wide variety of pressing ethical issues and dilemmas. It is important for health care professionals to assist stakeholders involved in the decisionmaking process using a respectful and sensitive approach to both identify and address these issues in a timely, effective and reflective manner. Ethical considerations and concerns reviewed in this chapter aim to promote professional attributes that compliment moral principles, professional standards and legal maxims in this unique therapeutic alliance. This section illustrates the multidimensional processes necessary to assist patients who require HMV. Some of these dimensions include QoL concerns for the patient and family members, advance care planning and caregivers' burden (11-15). There are many factors and considerations that must be examined and addressed to provide patients with the best possible care based on the patients' values and desires, while respecting the needs and health of caregivers.

\section{SECTION XIII. RECOMMENDATIONS}

1. Physicians must actively work collaboratively with the patient, family members and other health professionals involved in the health care decision-making process while at all times maintaining respect for patient autonomy, dignity and confidentiality. (Consensus)

2. It is important to proactively counsel capable patients and establish clear advanced directives (regarding issues such as crisis management and end-of-life care) in a timely manner, ensuring that patients fully understand and appreciate the reasonably foreseeable outcomes of their decisions. Physicians must work with patients to help prioritize their values, interests and preferences.(Consensus)
3. When considering the most appropriate location for ongoing ventilation issues relating to safety and the patient's values, beliefs and preferences must be the primary considerations for making such decisions providing optimal independence, respect for patient autonomy and increased quality of life. (Consensus)

4. In the event that the patient lacks decisional capacity regarding specific treatments, substitute decision-makers and clinicians must incorporate the patient's advance care directives in the decision-making process or, where there are no known advance care directives, to act in the patient's 'best interests'. (Consensus)

5. One must recognize one's own biases and endeavor to participate in a collaborative and fair decision-making process that primarily addresses, reflects and respects the values and wishes of the patient. (Consensus)

6. A plan of care should involve full-disclosure of pertinent information and a clear and coherent strategy, which would enable the patient to make fully informed decisions. This will allow any members participating in the patient's care to be held accountable for their duties and obligations. (Consensus)

7. Given the reality of scarce resources, any process of allocating limited care resources must be in accordance with distributive justice and due process. (Consensus)

8. The well-being of caregivers and the exhausting responsibilities of care must be considered. Caregivers should be supported, educated with regard to healthy coping strategies, and provided with some form of respite care whenever possible and desirable. (Consensus)

\section{REFERENCES}

1. Brooks D, Gibson B, Goldstein RS. The perspective of patients. In: Ambrosino N, Goldstein RS eds. Ventilatory Support for Chronic Respiratory Failure. New York: Informa Healthcare USA Inc, 2008.

2. Buckman RA. Breaking bad news: The S-P-I-K-E-S strategy. Psychosoc Oncol 2005;2:138-42.

3. Cano NJM, Roth H, Court-Ortuné I, et al. Nutritional depletion in patients on long-term oxygen therapy and/or home mechanical ventilation. Eur Respir J 2002;2030-7.

4. Romanow RJ. Shape the Future of Health Care: Interim Report. Saskatoon: Commission on the Future of Health Care in Canada, 2002.

5. Goldberg AI, Faure EAM, O'Callaghan JJ. High-technology home care: Critical issues and ethical choices. In: Monagle JF, Thomasma DC, eds. Health Care Ethics: Critical Issues for the 21st Century. Maryland: Aspen Publishers, 1998.

6. Goldberg AI. Non-invasive mechanical ventilation at home: Building upon the tradition. Chest 2002;121:321-4.

7. Goldstein RS, Psek JA, Gort EH. Home mechanical ventilation. Demographics and user perspectives. Chest 1995;108:1581-6.

8. Health Care Consent Act of Ontario, Canada (1996) c. 2, Sched. A, s. 21 (2).

9. Kent MA. The ethical arguments concerning the artificial ventilation of patients with motor neurone disease. Nurs Ethics 1996;3:317-28

10. Lang A, Edwards N, Hoffman C, et al. Broadening the patient safety agenda to include home care services. Healthcare Quarterly 9 (Special issue);2006;124-6.

11. Lindahl B, Sandman P, Rasmussen BH. Meanings of living at home on a ventilator. Nurs Inquir 2003;10:19-27.

12. MacAdam M. Home Care: It's Time for a Canadian Model. Healthcare Papers 2000;1:9-36.

13. Masotti P, Shortt S, Green M, et al. Adverse events in community care: Developing a research agenda. Healthcare Quarterly 2007;10:63-9.

14. McDonald ER, Hillel A, Wiedenfeld SA. Evaluation of the psychological status of ventilatory-supported patients with ALS/MND. Palliat Med 1996;10:35-41.

15. Moss AH, Oppenheimer EA, Casey P, et al. Patients with amyotrophic lateral sclerosis receiving long-term mechanical ventilation. Chest 1996;110:249-55. 
EDITORIAL INDEPENDENCE: The CTS receives unrestricted grants, which are combined into a central operating account to facilitate knowledge translation activities of all CTS Guideline Committees. Sources include the Canadian Institutes of Health Research, AstraZeneca Canada, GlaxoSmithKline Inc, Pfizer, Talecris and Boehringer Ingelheim Canada. Funds were specifically donated for the HMV Committee by the ALS Society of Canada, Muscular Dystrophy Canada, Respironics, Rick Hansen Foundation/Laval University, VIASYS Healthcare, VitalAire Canada Inc and West Care Medical. No sponsors played a role in the collection, review, analysis or interpretation of the scientific literature or in any decisions regarding the key messages presented in this document. As such, the CTS Home Mechanical Ventilation Committee is functionally and editorially independent from any funding sources of the CTS, and is accountable to the CTS Respiratory Guidelines Committee and the CTS Board of Directors.

CONFLICTS OF INTEREST: Members of the CTS Home Mechanical Ventilation Committee declared potential conflicts of interest at the time of appointment, and these were updated throughout the development process, in accordance with the CTS Conflict of Interest Disclosure Policy. Individual member conflict of interest statements are posted at www.respiratoryguidelines.ca/guideline/home-mechanical-ventilation-disease.
ACKNOWLEDGEMENTS: The authors thank the CTS for their invaluable administrative support, including specifically Director Janet Sutherland, and Guidelines Coordinators, Elena Goubanova, Stella Muthuri and Candice Brown. This guideline was developed under the aegis of the CTS Canadian Respiratory Guidelines Committee (CRGC), and we specifically thank the Chair, Dr Louis-Philippe Boulet, for his expertise and guidance throughout the guidelines process. Tom Oliver was instrumental with advice on guideline and consensus methodological issues. We thank our Canadian and International HMV Expert Peer Reviewers: Anita K Simonds MD FRCP, Royal Brompton and Harefield NHS Trust, United Kingdom; Emilio Servera MD FCCP, Hospital Clínico Universitario, Spain; Joao Carlos Winck MD PhD, Hospital São João, Portugal; Michael J Kampelmacher, MD PhD, University Medical Centre Utrecht, The Netherlands; Nicholas Hart, St Thomas' Hospital, Guy's and St Thomas' NHS Foundation Trust, United Kingdom; Roger S Goldstein MB ChB FCCP, West Park HealthCare Centre, Canada; Mark Herzog RRT, Canadian Society of Respiratory Therapists, Canada; David J Leasa, Critical Care \& Respirology, London Health Sciences Centre, Canada; Franz R Michel MD, Switzerland; RT M Sprooten MD, Centre of Home Ventilation, Maastricht University Medical Centre, The Netherlands; The Canadian Association of Physical Medicine \& Rehabilitation Spinal Cord Injury Special Interest Group; and the Canadian ALS Clinical Trials and Research Network. 


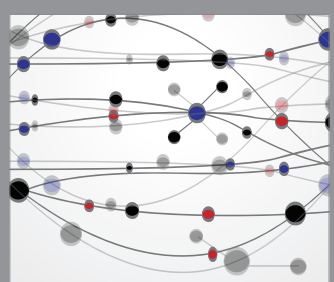

The Scientific World Journal
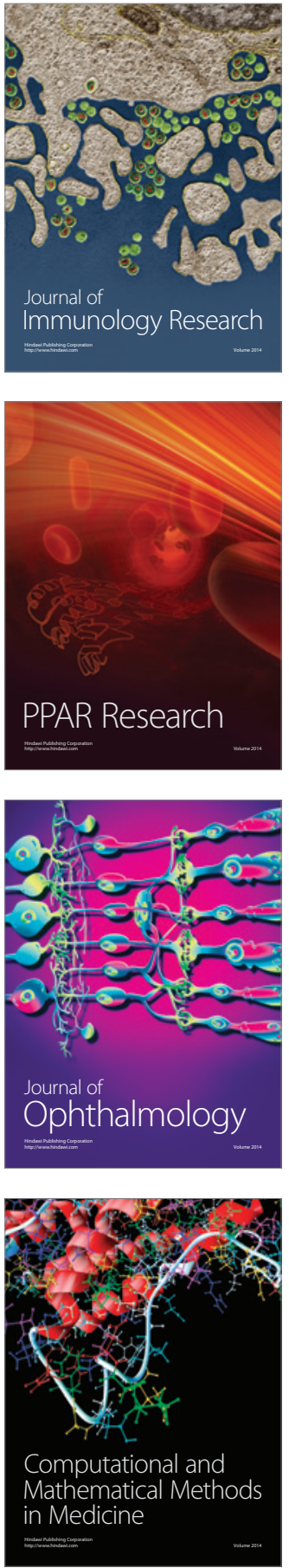

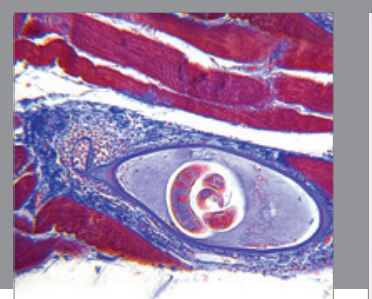

Gastroenterology Research and Practice

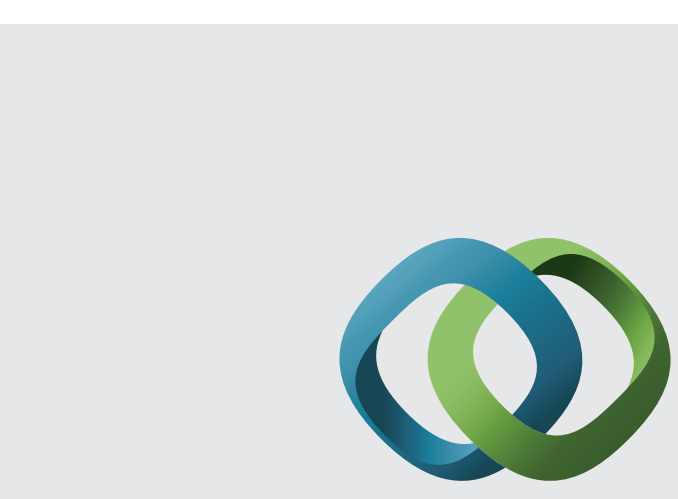

\section{Hindawi}

Submit your manuscripts at

http://www.hindawi.com
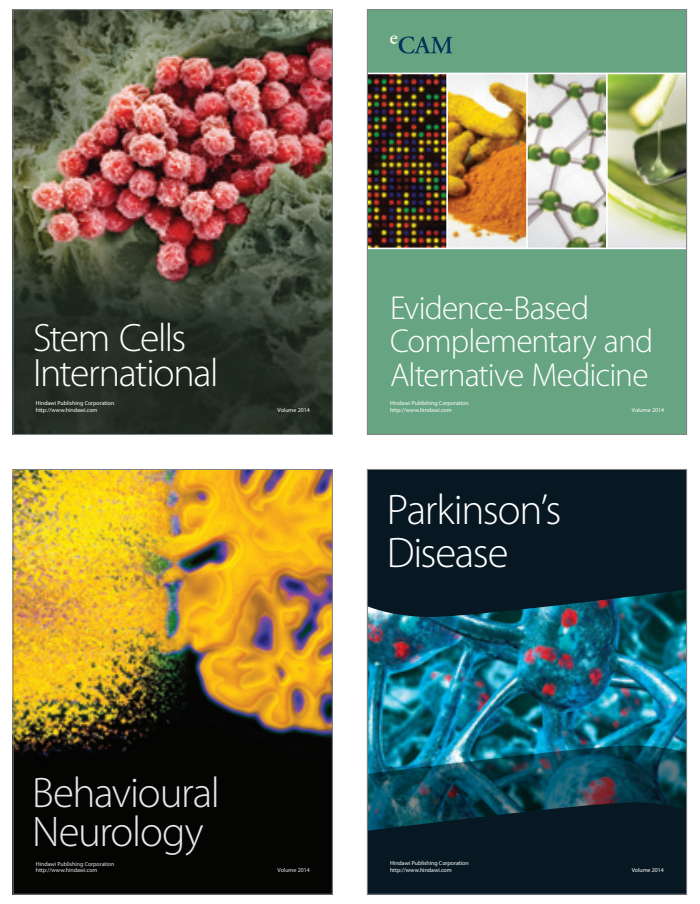
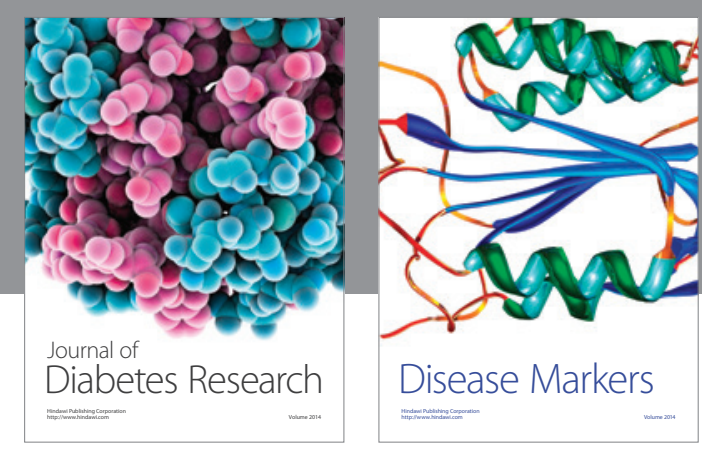

Disease Markers
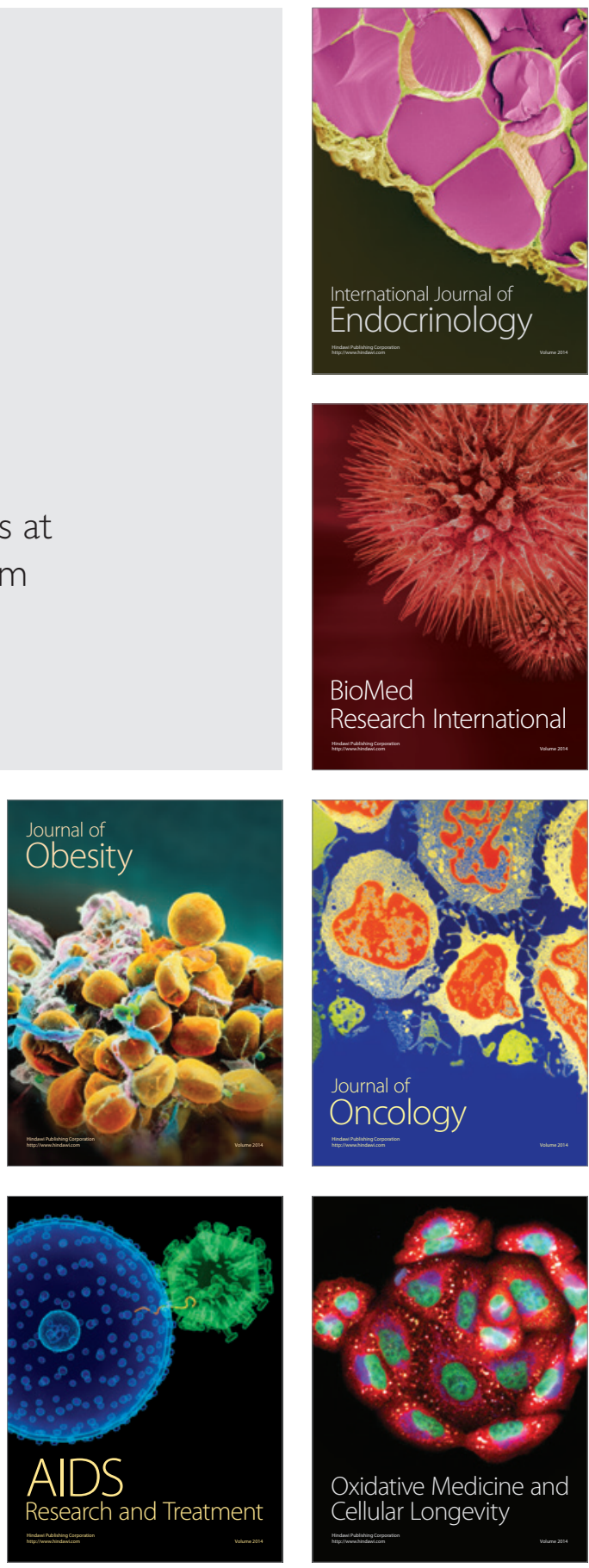